\title{
Uev1A-Ubc13 promotes colorectal cancer metastasis through regulating CXCL1 expression via NF-KB activation
}

\author{
Zhaojia Wu ${ }^{1}$, Heather Neufeld ${ }^{2}$, Eminao Torlakovic ${ }^{2,3}$ and Wei Xiao ${ }^{1}$ \\ ${ }^{1}$ Department of Microbiology and Immunology, University of Saskatchewan, Saskatoon S7N 5E5, Canada \\ ${ }^{2}$ Department of Pathology and Laboratory Medicine, University of Saskatchewan, Saskatoon S7N 5E5, Canada \\ ${ }^{3}$ Current address: Department of Laboratory Hematology, Toronto General Hospital/UHN, Toronto M5G 2C4, Canada \\ Correspondence to: Wei Xiao, email: wei.xiao@usask.ca
}

Keywords: colorectal cancer; metastasis; Uev IA; NF-KB; CXCLl

Received: May 01, $2017 \quad$ Accepted: February 20, $2018 \quad$ Published: March 23, 2018

Copyright: Wu et al. This is an open-access article distributed under the terms of the Creative Commons Attribution License 3.0 (CC BY 3.0), which permits unrestricted use, distribution, and reproduction in any medium, provided the original author and source are credited.

\section{ABSTRACT}

Colorectal cancer is the second most common cause of cancer-related death worldwide. Uncontrolled growth and distant metastasis are hallmarks of colorectal cancer. However, the precise etiological factors and the mechanisms are diverse and still largely unclear. The potential proto-oncogene UEV1A encodes a ubiquitin conjugating enzyme variant, which is required for Ubc13-catalyzed K63-linked polyubiquitination of target proteins and the activation of NF-кB, a transcription factor known to be involved in innate immunity, anti-apoptosis, inflammation and cancer. In order to understand the roles of Uev1A in colon cancer progression, we experimentally manipulated the Uev1A level in HCT116 colon cancer cells and found that UEV1A overexpression alone is sufficient to promote invasion in vitro and metastasis in vivo. This process is mediated by NF-KB activation and depends on its physical interaction with Ubc13. No expression of Uev1A was detected in histologically normal human colonic mucosa, but its expression was detected in human colorectal adenocarcinoma, which was closely correlated with nuclear p65 levels, an indicator of NF-KB activation. Uev1A protein was detected in $46 \%$ of primary tumors and $79 \%$ of metastatic tumors examined. Our experimental data establish that among NF-KB target genes, Uev1Aregulated CXCL1 expression plays a critical role in colon cell invasion and metastasis, a notion supported by the colon adenocarcinoma survey. Furthermore, experimental depletion of Uev1 in HCT116 cells reduces CXCL1 expression, and prevents cell invasion and tumor growth in a xenograft mouse model. These results identify Uev1A as a potential therapeutic target in the treatment of metastatic colorectal cancers.

\section{INTRODUCTION}

UEV1 (also known as CROC1 or CIR1), encoding a ubiquitin (Ub)-conjugating enzyme variant (Uev), was identified as a mammalian homolog of yeast MMS2 [1], as well as a gene whose expression was positively corelated to tumorigenesis in various screens [2-4]. A Uev (Uev1 or Mms2) is a cofactor and absolutely required for Ubc13mediated K63-linked polyubiquitin chain assembly [5-8]. UEV1 encodes at least three splicing variants, among which Uev1A and Uev1C are able to form a complex with
Ubc13 and promote K63-linked polyubiquitination but differ in that Uev1 A contains thirty additional amino acids at the N-terminus $[9,10]$.

Although Uev1A and Mms2 have similar biochemical activity, they appear to function differently in mammalian cells: Ubc13-Mms2 is required for DNAdamage response whereas Ubc13-Uev1A is involved in NF- $\kappa B$ activation [10]. The Uev1A-Ubc13 heterodimer acts downstream of tumor-necrosis factor (TNF) receptors along with TNF-associated factor 6 (TRAF6) $[11,12]$ and TRAF2 [13] to polyubiquitinate NEMO/IKK $\gamma[14,15]$ 
and/or RIP1 [16] to activate IKK. Activated IKK leads to the phosphorylation and degradation of $I \kappa B \alpha$, resulting in the release of NF- $\mathrm{BB}$ RelA (p65) subunits to translocate into the nucleus [17]. NF- $\mathrm{KB}$ is a sequence-specific transcription factor known to be involved in innate immunity, anti-apoptosis and inflammation [18-20], and its uncontrolled activation is associated with cancers $[21,22]$. Previous studies reported that Ubc13-Uev1A inhibits stress-induced apoptosis in HepG2 cells [23] and overexpression of UEV1A in MDA-MB-231 cells is sufficient to induce metastasis both in vitro and in vivo primarily through regulating matrix metalloproteinase-1 $(M M P 1)$ gene expression [9]. Both functions are regulated by NF- $\mathrm{kB}$ activation and require functional Ubc13. These observations collectively establish a close correlation between UEVIA expression and tumorigenic potential.

In fact, many previous studies implicate UEV1 as a potential proto-oncogene. UEV1 maps to chromosome $20 q 13.2$ [4], a region where DNA amplification is frequently reported in breast cancers [24-26] and other tumors [27], as well as in virus-transformed immortal cells [28]. UEV1 was identified as a transactivator of the $c$-fos promoter [3]. It is down-regulated when HT29-M6 colon cancer cells undergo chemical-induced differentiation [4], and up-regulated when SV40-transformed human embryonic kidney cells become immortal [2]. Furthermore, UEVI is variably up-regulated in all tumor cell lines examined $[1,9]$. It was reported that a small-molecule inhibitor of Ubc13-Uev1A interaction can inhibit proliferation and survival of diffuse large B-cell lymphoma cells [29]. Although elevated expression of UEV1 has been reported in various human tumors, the role of $U E V 1$ in human colorectal cancers (CRCs) is poorly understood.

In this study we demonstrate that in HCT116 colon cancer cells, the UEV1A transcript level is moderately elevated compared to normal colon cells, that elevated Uev1A levels are frequently observed in primary and metastatic colon cancers, and that, more importantly, elevated Uev1A is highly correlated with the nuclear translocation of the $\mathrm{p} 65$ subunit of NF- $\mathrm{\kappa B}$ in human colon cancer samples. Indeed, experimental overexpression of UEV1A alone in HCT116 cells is sufficient to activate $\mathrm{NF}-\mathrm{KB}$, which in turn up-regulates the $C X C L 1$ expression to enhance colon cancer cell metastasis. On the other hand, experimental depletion of Uev1 in HCT116 cells reduces CXCL1 expression, cell invasion in vitro and the ability to grow tumors in a xenograft mouse model. These observations suggest a potential therapeutic target in the treatment of metastatic colon cancers.

\section{RESULTS}

\section{$U E V 1 A$ is overexpressed in colon cancers}

To investigate the role of UEV1A in human colon cancers, we examined relative transcript levels of UEVIA and $U E V 1 C$ in colon cancer lines using human normal colon cell CCD-33Co as a reference. Interestingly, the UEV1A transcript level is elevated in all colon cancer cell lines examined (Figure 1A, left), with no more than twofold upregulation of UEVIC in these lines (Figure 1A, right).

It has been previously reported that elevated expression of UEVIA may promote tumor growth and metastasis in a breast tumor model [9]. We next assessed relative UEV1A expression in normal and malignant colon tumors by immunohistochemistry (IHC) using a Uev1A-specific monoclonal antibody LN1 against formalin-fixed/paraffin-embedded tissue samples, based on a blind scoring scale as shown in Supplementary Figure 1. In general, normal colonic mucosa does not express Uev1A, but its expression is frequently detected in human colon adenocarcinoma, while metastatic tumors showed significantly stronger staining for Uev1A than in primary colon adenocarcinoma (Pearson Chi-Square Test, $p<0.001$ ). For example, only $3 / 31$ benign samples showed weak focal expression of Uev1A, while samples of primary colon carcinoma were positive in 21/46 (46\%), and metastatic colon carcinoma was positive in $44 / 56$ $(79 \%)$ cases (Figure 1B). Of particular interest is that in occasional cases where both normal and tumorigenic tissues are present in the same patient sample, Uev1A expression is specifically observed in the tumorigenic tissues but not in normal tissues (Figure 1C). The above observations collectively indicate that UEVIA is frequently overexpressed in colon cancers.

\section{$U E V 1 A$ regulates colon cancer cell invasion in vitro and metastasis in a xenograft model}

To ask whether an elevated UEVIA level alone is sufficient to promote colon tumorigenesis, UEV1A, UEV1C or MMS2 genes were cloned into a pcDNA4.0/TO/ $\mathrm{HA}(+)$ vector and then transfected into HCT116-TR cells to create stable cell lines, and the level of ecotopic gene expression after $10 \mu \mathrm{g} / \mathrm{ml}$ doxycycline (Dox) treatment was monitored by qRT-PCR (Figure 2A) and by western blot against the HA tag (Figure 2B). We also created a stable HCT116-TR cell line expressing Dox-inducible Uev1A-F38E mutant protein (Figure 2A and 2B) that abolishes its interaction with Ubc13 and thus its ability to promote Ubc13-mediated K63 polyubiquitination [8].

The cell growth of stable HCT116-TR transfectants was first measured, with no significant alterations among each group in 6 days (Supplementary Figure 2). The effects of ecotopic gene expression on colon cancer cell invasion were then measured. In a transwell assay, the invasiveness of UEV1A transfectants was approximately 1.85 -fold higher than the control, UEVIC or MMS2 transfectants, whereas there is no significant difference among control, UEVIC and $M M S 2$ transfectants (Figure 3A and 3B). Furthermore, we overexpressed UEVIA in another colon cancer cell line, 
DLD1 (Supplementary Figure 3A, 3B). The invasiveness of UEV1A transfectants was approximately 1.66-fold higher than the control in DLD1 cells as measured by the transwell assay (Supplementary Figure 7D). These results suggest that $U E V 1 A$ but not $U E V 1 C$ or $M M S 2$ promotes colon cancer cell invasion in vitro.
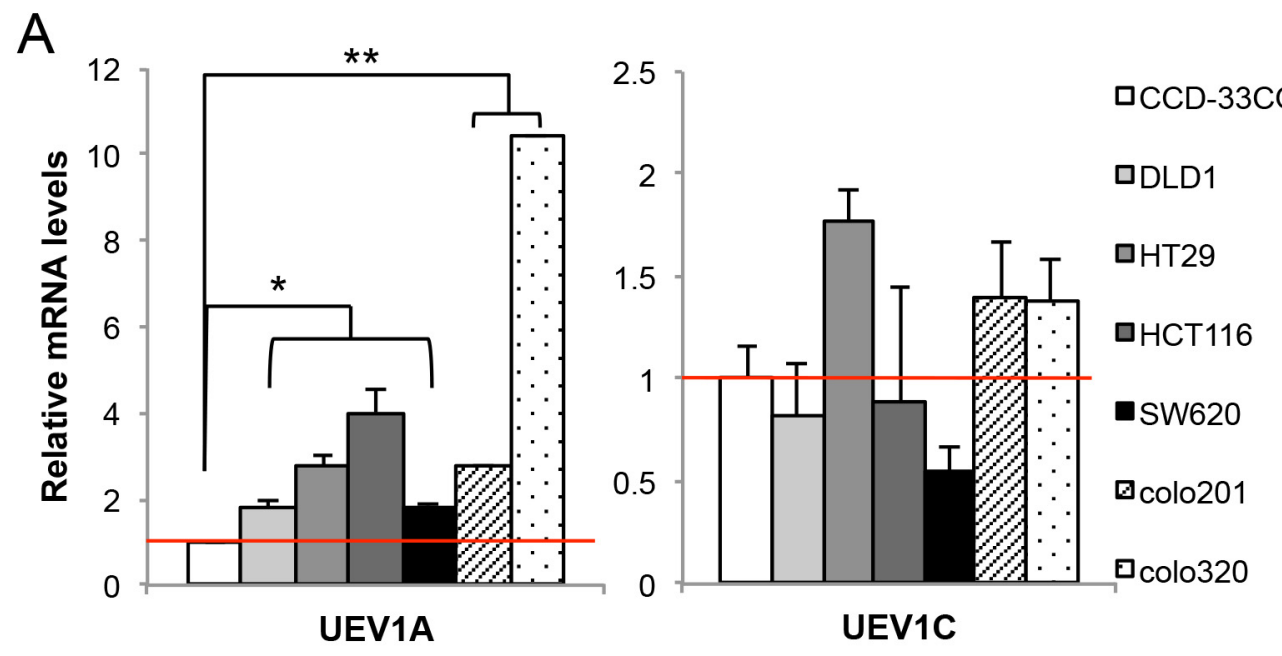

B

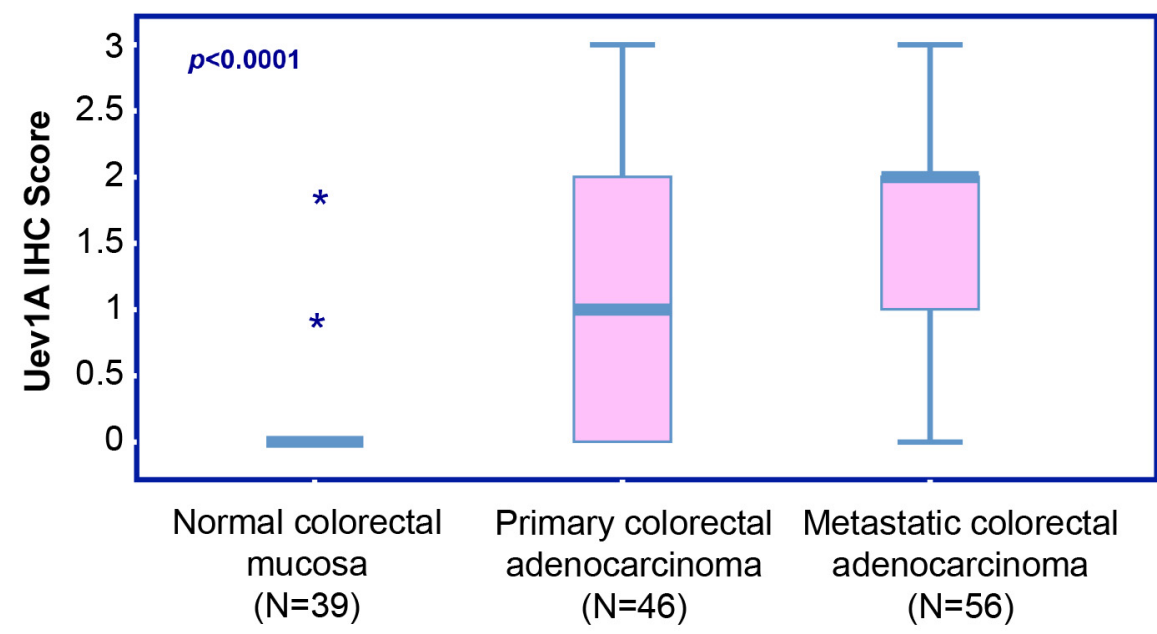

C
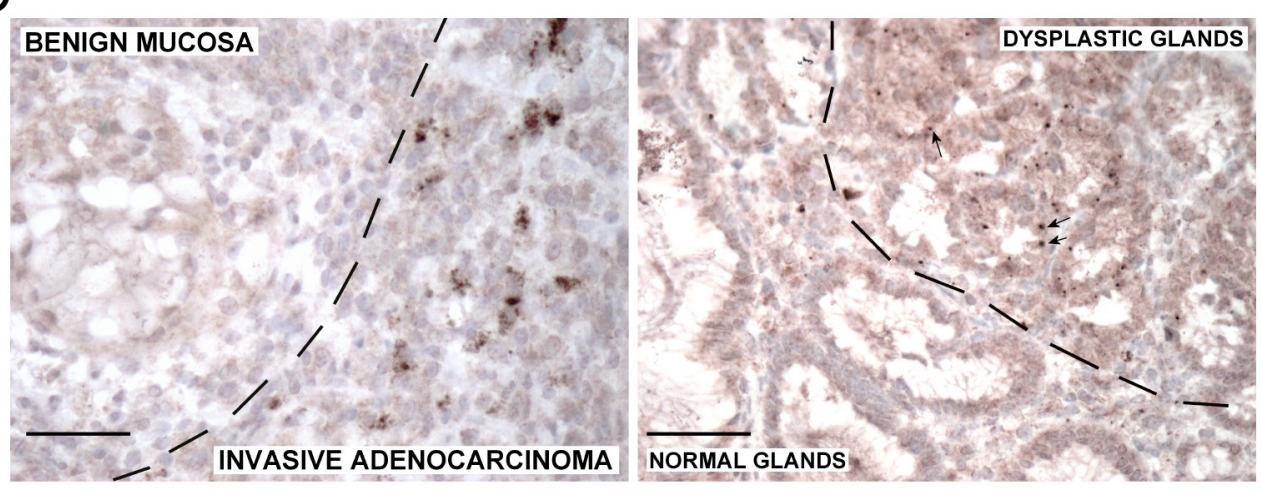

Figure 1: $U E V 1 A$ is overexpressed in human colon cancer cell lines and tumor samples. (A) Relative transcript levels of $U E V 1 A$ and $U E V 1 C$ variants in human colon cancer cell lines as determined by qRT-PCR. $\left({ }^{*} P<0.05,{ }^{* *} P<0.01\right)$ (B) Relative cellular Uev1A level as determined by immunohistochemistry using a Uev1A-specific antibody (LN1) against formalin-fixed/paraffin-embedded human colon carcinoma samples. (C) Representative IHC images containing both normal and tumor tissues showing differential LN1 staining. Dotted lines indicate border of normal and tumor tissues. Scale bar $=50 \mu \mathrm{m}$. 

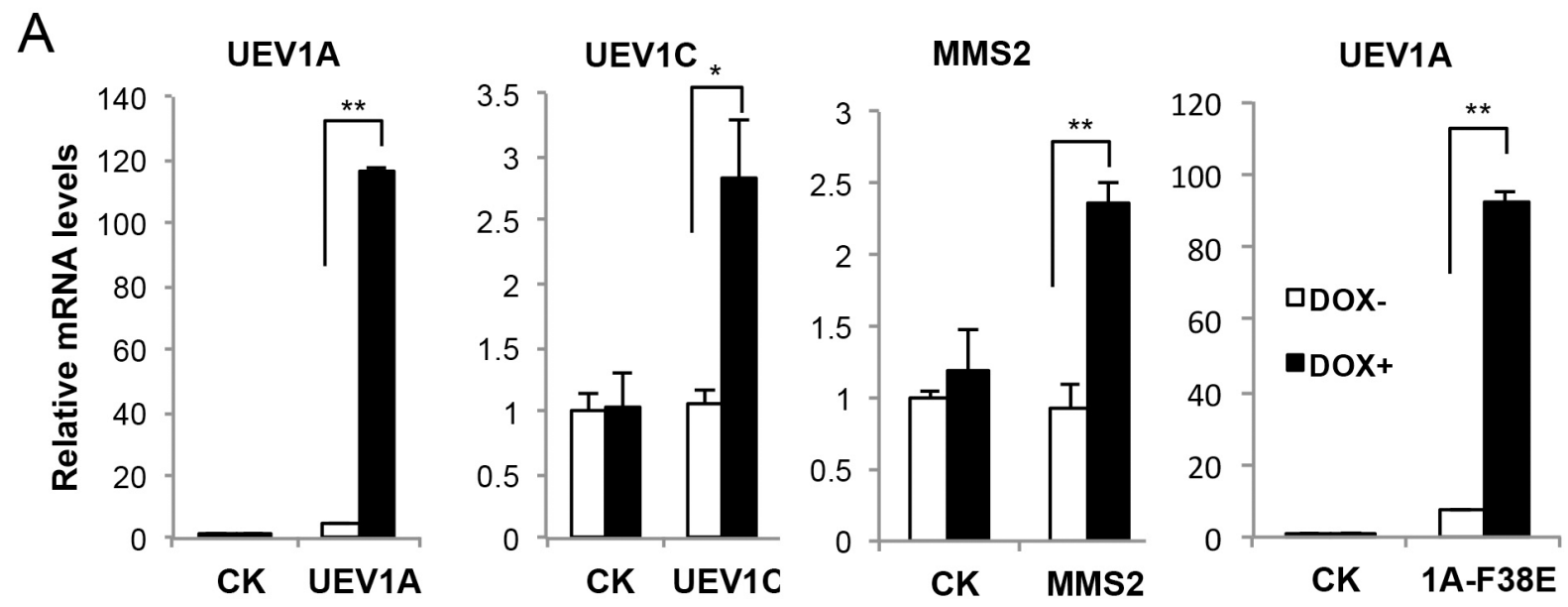

B
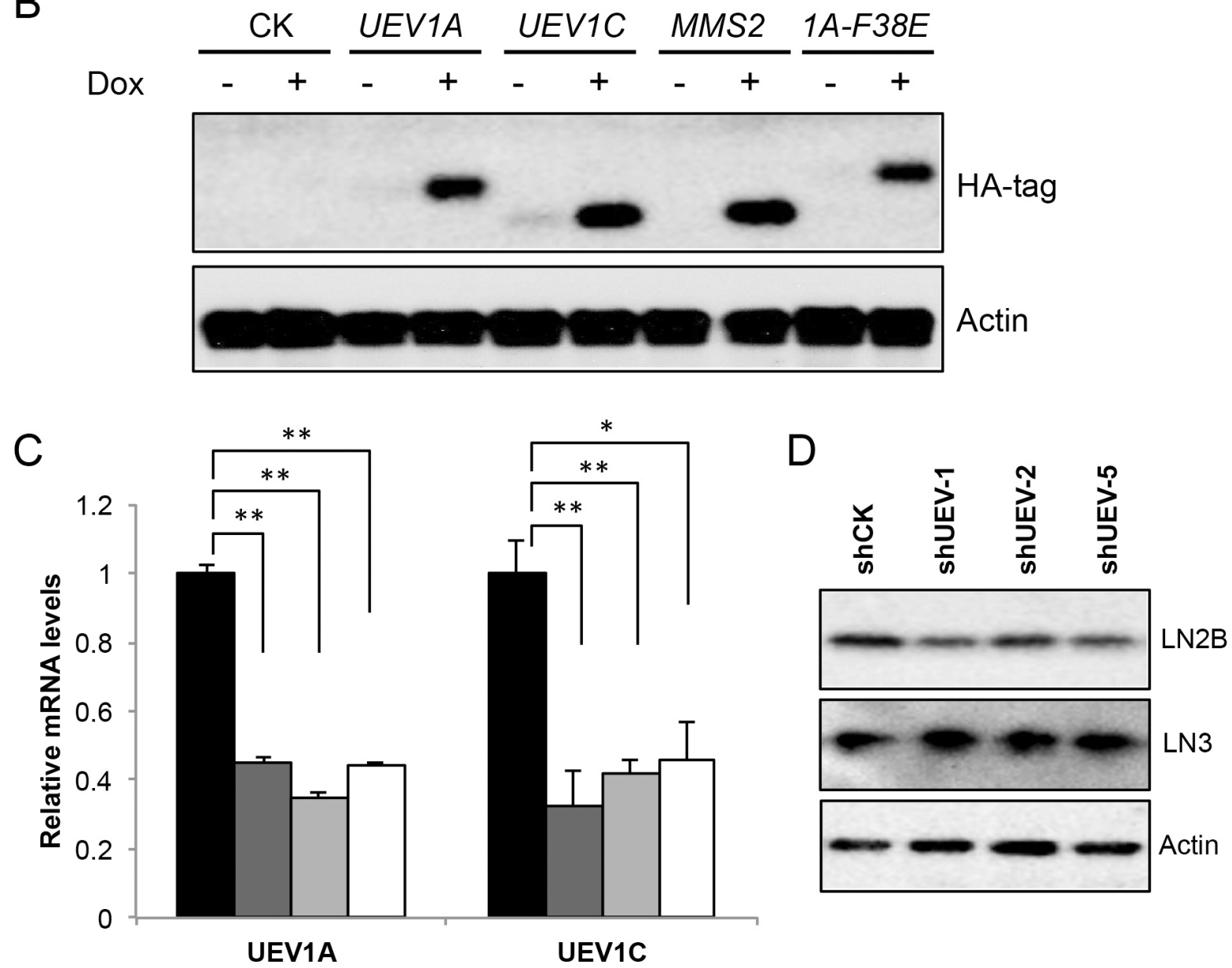

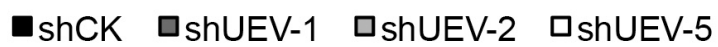

Figure 2: Manipulation of $\boldsymbol{U} \boldsymbol{E} \boldsymbol{V}$ expression levels in HCT116 cells. cDNA4.0/TO/HA(+) vector expressing $U E V 1 A, U E V 1 C$, $M M S 2$, mutated UEV1A (1A-F38E) or vector only (CK) was stably transfected into HCT116-TR cells, with or without Dox treatment. The level of ectopic gene expression was monitored (A) by qRT-PCR and (B) by western blot against an anti-HA antibody. (C) UEV1A and UEV1C transcript levels in shCK and shUEV1 lines were determined by qRT-PCR. HCT116 cells were transfected with shRNA lentiviral particles against UEV1 (shUEV1) or non-specific target (shCK). 20 single colonies were picked and subcultured. shUEV1-1, shUEV1-2 and shUEV1-5 represent three independent stable shUEV1 lines. (D) Uev1C and Mms2 levels in shCK and shUEV1 lines were determined by western blot against anti-Uev1 (LN2B) and MMS2+Uev1 (LN3) antibodies. ${ }^{*} P<0.05,{ }^{* *} P<0.01$. 
Table 1A: Correlation of cytoplasmic Uev1A levels with nuclear p65

\begin{tabular}{lccccc}
\hline \multirow{2}{*}{ Nuclear p65 } & \multicolumn{1}{c}{ Uev1A } & (LN1) & \multirow{2}{*}{ Total } \\
\cline { 2 - 5 } & $\mathbf{0}$ & $\mathbf{1}$ & $\mathbf{2}$ & $\mathbf{3}$ & \\
\hline $\mathbf{0}(\mathbf{H S}<\mathbf{1 0})$ & 9 & 2 & 2 & 0 & 13 \\
$\mathbf{1}(\mathbf{H S}=\mathbf{1 0 - 1 0 0 )}$ & 6 & 6 & 16 & 5 & 33 \\
$\mathbf{2}(\mathbf{H S}=\mathbf{1 0 1 - 2 0 0})$ & 7 & 12 & 15 & 6 & 40 \\
$\mathbf{3}(\mathbf{H S}=\mathbf{2 0 1 - 3 0 0})$ & 3 & 4 & 3 & 6 & 16 \\
Total & 25 & 24 & 36 & 17 & 102 \\
\hline
\end{tabular}

Tumor samples only $(P=0.008)$.

Table 1B: Correlation of cytoplasmic Uev1A levels with nuclear p65

\begin{tabular}{lccccc}
\hline \multirow{2}{*}{ Nuclear p65 } & & Uev1A & (LN1) & \multirow{2}{*}{ Total } \\
\cline { 2 - 5 } & $\mathbf{0}$ & $\mathbf{1}$ & $\mathbf{2}$ & $\mathbf{3}$ & \\
\hline $\mathbf{0}$ & 37 & 8 & 1 & 0 & 46 \\
$\mathbf{1}$ & 3 & 3 & 1 & 1 & 8 \\
$\mathbf{2}$ & 1 & 1 & 0 & 0 & 2 \\
$\mathbf{3}$ & 0 & 0 & 0 & 0 & 0 \\
Total & 41 & 12 & 2 & 1 & 56 \\
\hline
\end{tabular}

Normal tissues only $(P<0.001)$.

As an increased ability of cancer cells to invade in vitro may indicate an increased ability to cause cell metastasis, to further address the correlation between UEVIA expression and colon cancer metastasis, we assessed the effects of UEVIA on metastasis using an in vivo xenograft mouse model. Stably-transfected HCT116-TR cells were injected into the lateral flanks of 4- to 5-week-old female athymic nude mice and 625 $\mathrm{mg} / \mathrm{kg}$ Doxycycline (Dox) was added in feed as soon as the cells were injected. Tumor growth and metastasis were then monitored. Compared to those injected with either vector, UEVIC or MMS2, the mice injected with the UEV1A-expressing cells had metastasis tumors on many organs, such as spleen, liver, kidney, stomach/ esophagus and diaphragm/peritoneum (Figure 3C and Supplementary Figure 4). In contrast, there was no tumor metastasis in mice injected with $M M S 2$-expressing cells or cells expressing mutated UEV1A-F38E. One of ten mice injected with vector control cells developed kidney metastasis and one of ten mice injected with UEVICexpressing cells developed an metastasis tumor on shoulder. Furthermore, overexpression of UEV1A but not $U E V 1 C$ or $M M S 2$, accelerated tumor growth compared to vector-transfected cells (Figure 3D).

The endogenous UEV1 expression in HCT116 cells was suppressed by using an shRNA designed against UEV1 (shUEV1) delivered by lentiviral particles. 20 independent colonies were picked and individually subcultured. The expression levels of UEV1A, UEVIC or
MMS2 were determined by qRT-PCT. It was found that 3 shUEV1 colonies, shUEV1-1, shUEV1-2 and shUEV1-5, reduced UEV1A expression to $45 \%, 35 \%$, and $44 \%$ of control shRNA-treated cells, respcetively (Figure 2C). As expected, the cellular UEV1C mRNA and protein levels were also reduced (Figure 2C and 2D) but the $M M S 2$ expression remains unaffected (Figures 2D and Supplementary Figure 5A).

Partial depletion of Uev1 reduced cell invasion (Figures 3E and Supplementary Figure 5B). The above findings were further extended by using a xenograft mouse model, in which depletion of Uev1 limited tumor growth (Figure 3F), and like the control group, no metastasis to any organs was observed (data not shown). These results collectively indicate that elevated UEV1A expression in HCT116 cells plays a critrical role in colon cancer tumorigenesis and metastasis.

\section{Overexpression of $U E V 1 A$ activates NF- $\mathrm{KB}$ in colon cancer cells in a Ubc13-dependent manner}

To understand the mechanism by which Uev1A promotes metastasis in colon cancer cells, we took into account that Uev1A has been reported to activate NF- $\kappa \mathrm{B}$ in HepG2 cells [23], and that, once released into the nucleus, NF- $\mathrm{KB}$ regulates the expression of a large number of genes critical for tumorigenesis, inflammation and metastasis [21]. Our previous research also reveals that Uev1A can promote breast cancer metastasis though 
NF- $\kappa \mathrm{B}$ activation [9]. IHC, which was performed in 102 colon tumor samples (Table 1A) and 56 normal tissue samples (Table 1B), reveals a close correlation between $U E V 1 A$ overexpression and $\mathrm{NF}-\kappa \mathrm{B}$ activation as judged by the nuclear translocation of the $\mathrm{p} 65$ subunit of NF- $\kappa \mathrm{B}$ (Spearman correlation, $\mathrm{r}=0.389, p<0.0001$ for all tissues).

Since a hallmark of NF- $\kappa \mathrm{B}$ activation is its translocation from cytoplasm to the nucleus, we
A
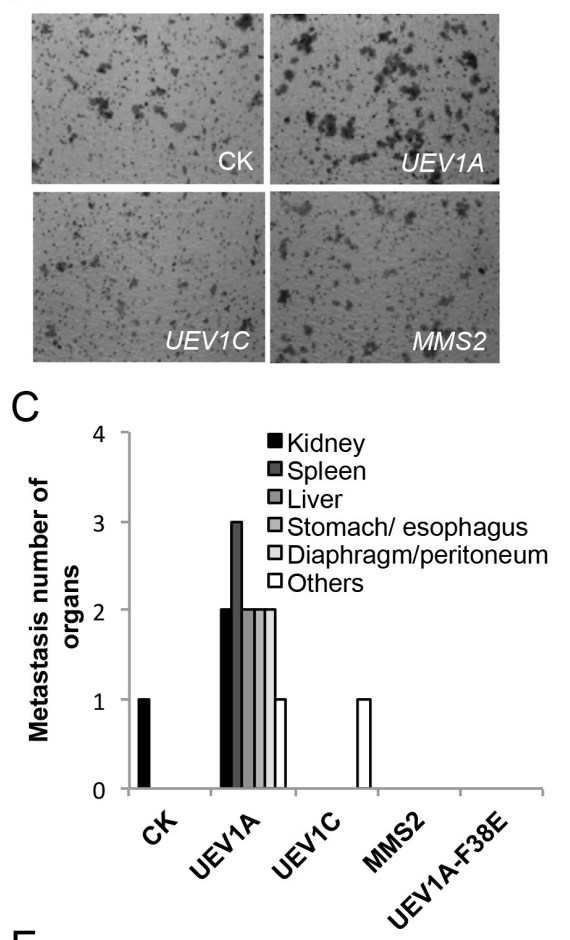

$\mathrm{E}$

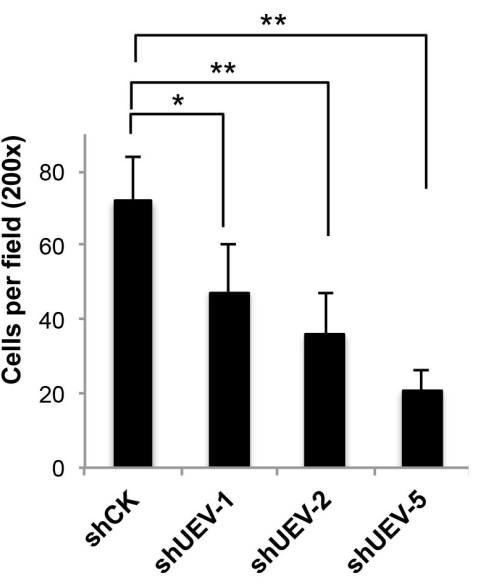

B

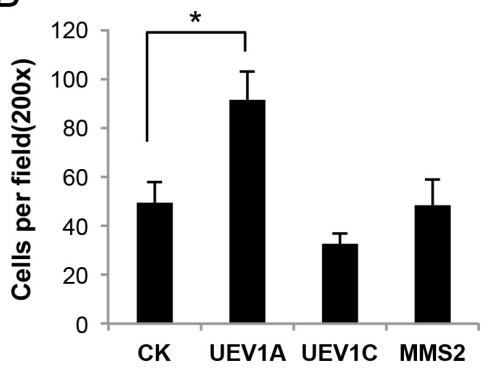

D

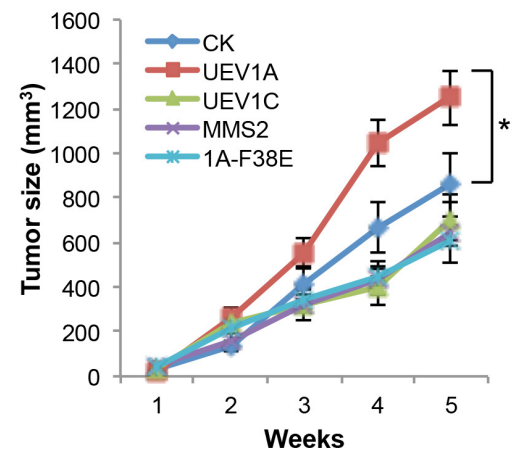

$\mathrm{F}$

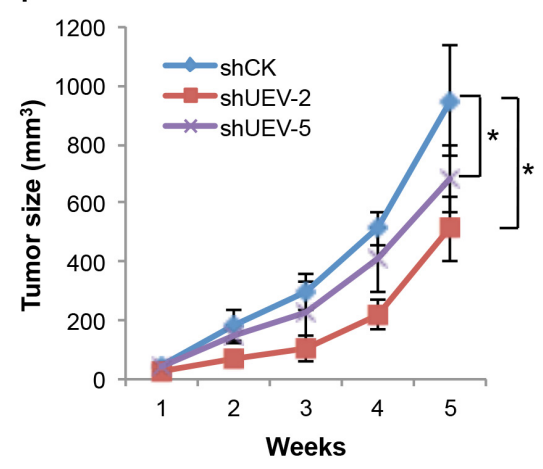

Figure 3: Experimental manipulation of $U E V 1 A$ expression alters HCT116 cell invasion in vitro and metastasis in a xenograft mouse model. (A) Representative images of cell invasion assay with Matrigel-coated transwells in vector control (CK), UEV1A, UEV1C or MMS2 stably-transfected HCT116-TR cells with Dox treatment. (B) Statistical analysis of the cell invasion assay data. Cells that invaded the lower surface of the filter were counted in 5 random fields under a light microscope at 200x magnification $\left({ }^{*} P<0.05\right)$. (C) In vivo tumorigenesis and metastasis assays using a xenograft mouse model. $1 \times 10^{6}$ HCT116-TR cells collected from each treatment were injected into the lateral flanks of 4- to 5-week-old female athymic nude mice. Five weeks after injection, organ samples were taken after sacrifice. Quantitative analysis of the in vivo organ metastasis as measured by the number of metastatic organs $(\mathrm{n}=5)$. (D) In vivo tumorigenesis assays using a xenograft mouse model. Tumor growth was measured every week after injection (Day 0) and expressed as mean $\pm \mathrm{SD}(\mathrm{n}=10),\left({ }^{*} P<0.05\right)$. (E) Quantitative analysis of cell invasion in Matrigel-coated transwells. Cells that invaded the lower surface of the filter were counted in 5 random fields under a light microscope at 200x magnification $\left({ }^{*} P<0.05\right.$, $\left.{ }^{* *} P<0.01\right)$. (F) The in vivo tumorigenesis assay using a xenograft mouse model. $1 \times 10^{6}$ HCT116 cells depleted with shUEV1 or shCK were injected into the lateral flanks of 4 to 5 -week-old female athymic nude mice. Tumor growth was measured every week after injection (Day 0$)$ and expressed as mean $\pm \mathrm{SD}(\mathrm{n}=10),\left({ }^{*} P<0.05\right)$. 
transfected HCT116-TR cells with a variety of constructs, induced the target gene expression by adding Dox, fractionated cells and then measured the subcellular distribution of the p65 subunit of NF- $\mathrm{kB}$. As seen in Figure $4 \mathrm{~A}$, only overexpression of $U E V 1 A$, but not $U E V 1 C$ or $M M S 2$, was able to increase the phosphorylation of the
A
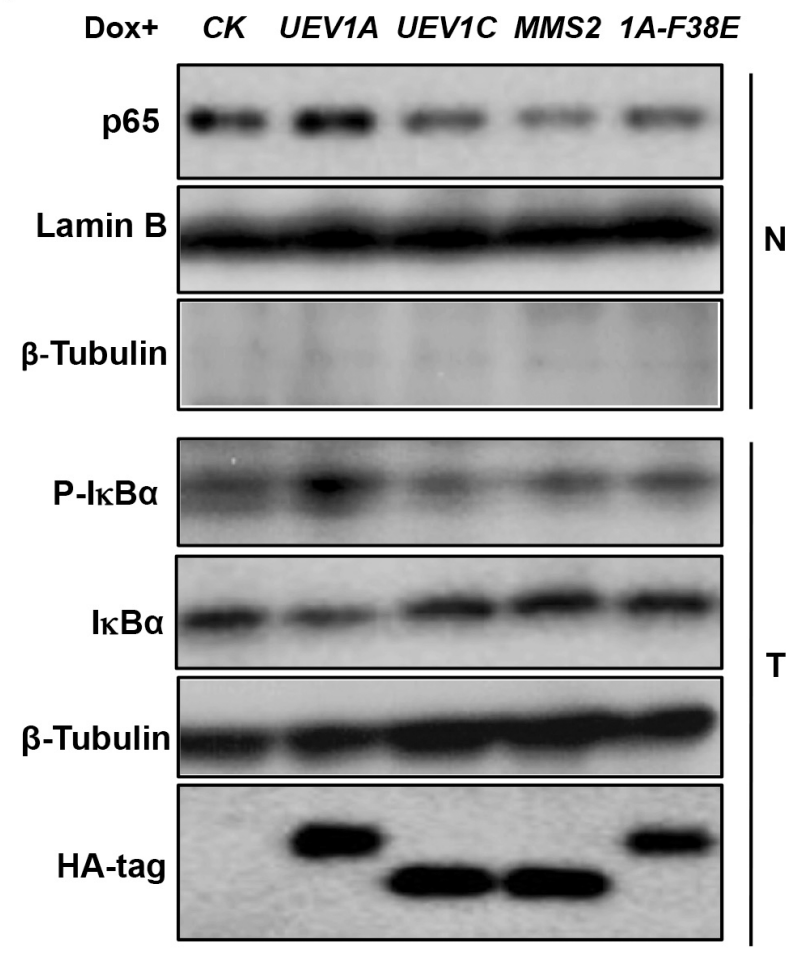

B

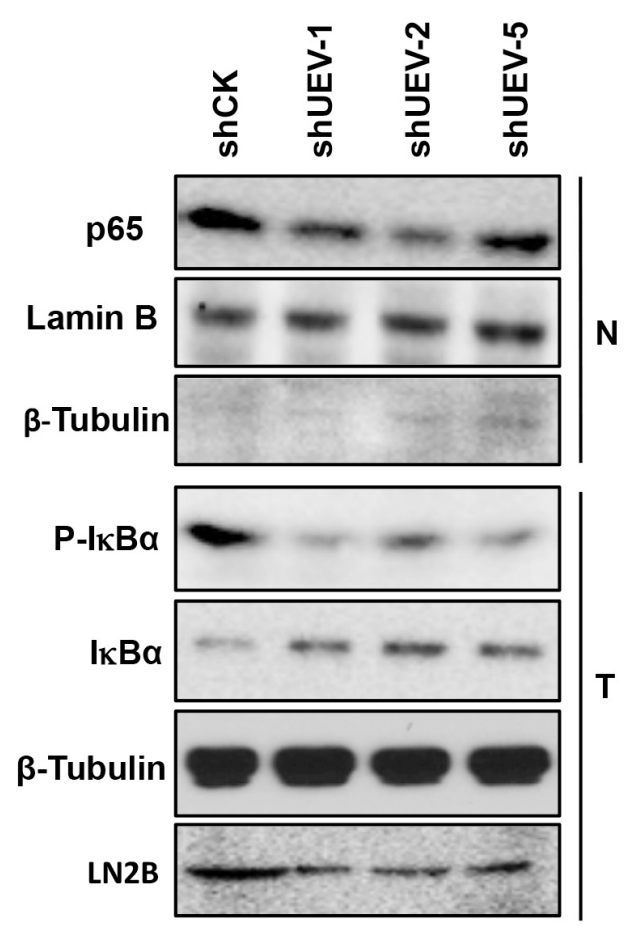

E
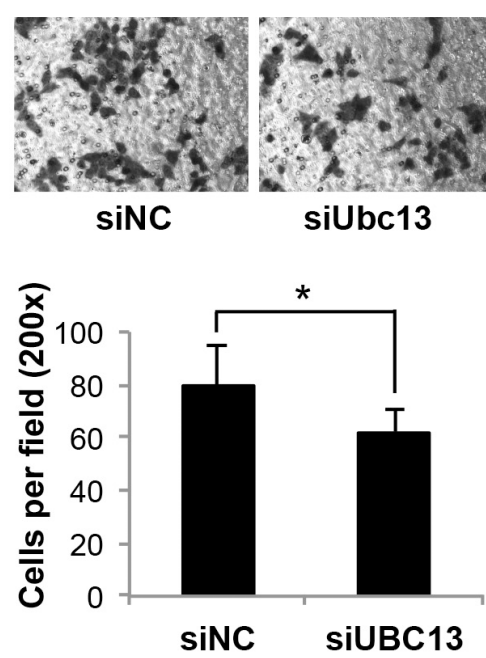

Figure 4: Uev1A activates NF- $\kappa B$ in colon tumors and HCT116 cells in a Ubc13-dependent manner. (A) NF- $\kappa B$ activation in $U E V$-overexpressing cells. Nuclear $(\mathrm{N})$ or whole-cell $(\mathrm{T})$ extracts were prepared and equal amounts of protein were separated by SDSPAGE gel, followed by western blotting analysis using an anti-p65 antibody to measure NF-кB nuclear enrichment, an anti-P(S32)-IкB $\alpha$

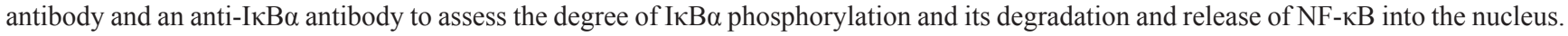
(B) NF- $\mathrm{KB}$ activation in Uev1-depleted cells. Experimental conditions are as described in (A). (C) Uev1A-F38E (1A-F38E) fails to interact with Ubc13 as judged by a co-IP assay. (D) NF- $\mathrm{KB}$ activation in Ubc13-depleted cells. Experimental conditions are as described in (A). (E) Cell invasion assay with Matrigel-coated transwells in Ubc13 depleted and UEV1A overexpressed cells. Top panel, representative images; lower panel, quantitative analysis $\left({ }^{*} P<0.05\right)$. 
$\mathrm{NF}-\kappa \mathrm{B}$ inhibitor I $\mathrm{B} \mathrm{B} \alpha$, decrease cellular $\mathrm{I} \kappa \mathrm{B} \alpha$ and enrich p65 in the nucleus. Consistently, depletion of Uev1 by shRNA reduced $\mathrm{I} \kappa \mathrm{B} \alpha$ phosphorylation and p65 nuclear translocation (Figure 4B). Similar to HCT116, only overexression of $U E V 1 A$, but not $U E V 1 C$ or $M M S 2$ was able to increase the phosphorylation of $\mathrm{I} \kappa \mathrm{B} \alpha$, decrease $\mathrm{I} \kappa \mathrm{B} \alpha$ and promote more $\mathrm{p} 65$ into the nucleus in DLD1 cells (Supplementary Figure 3C).
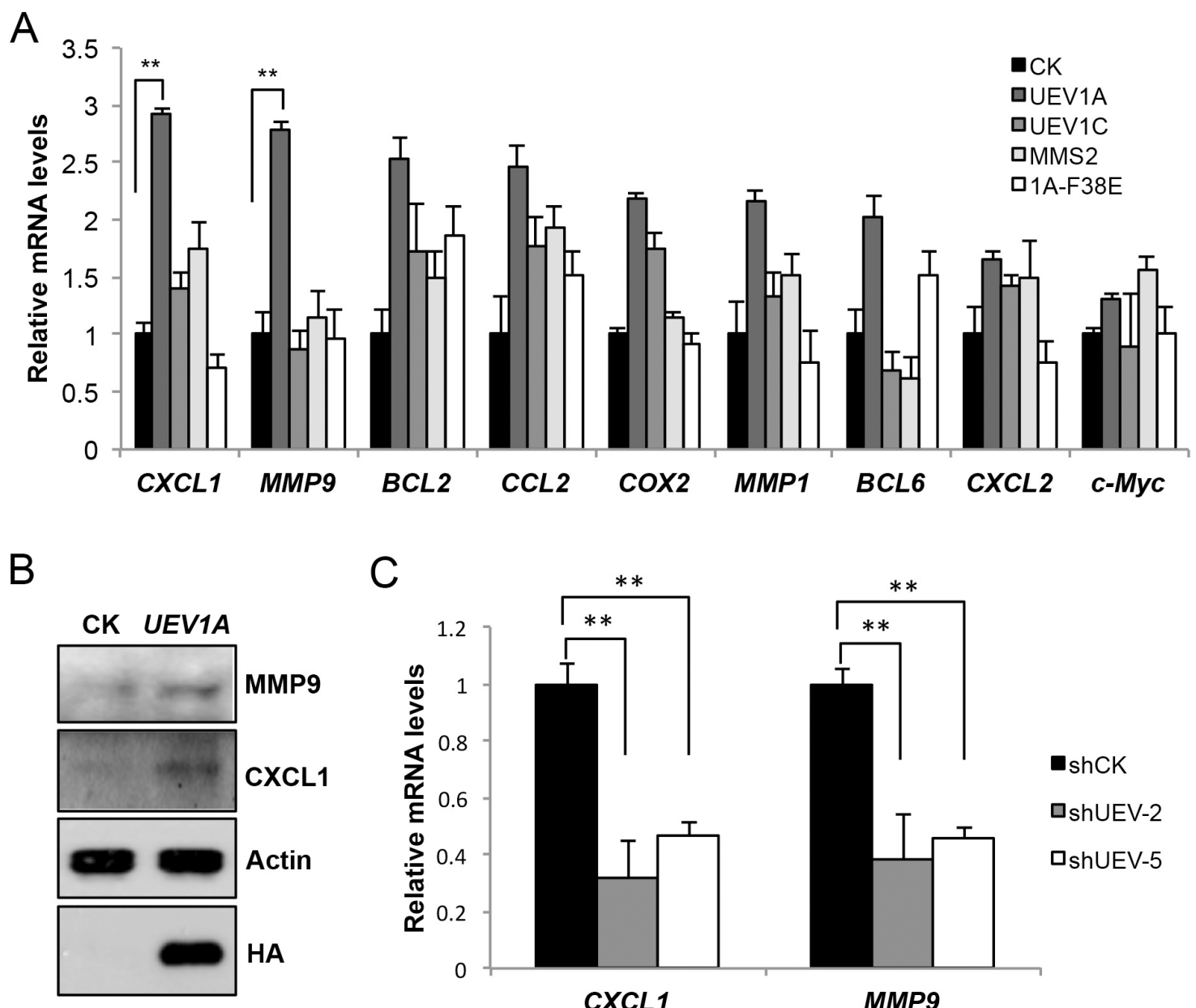

C
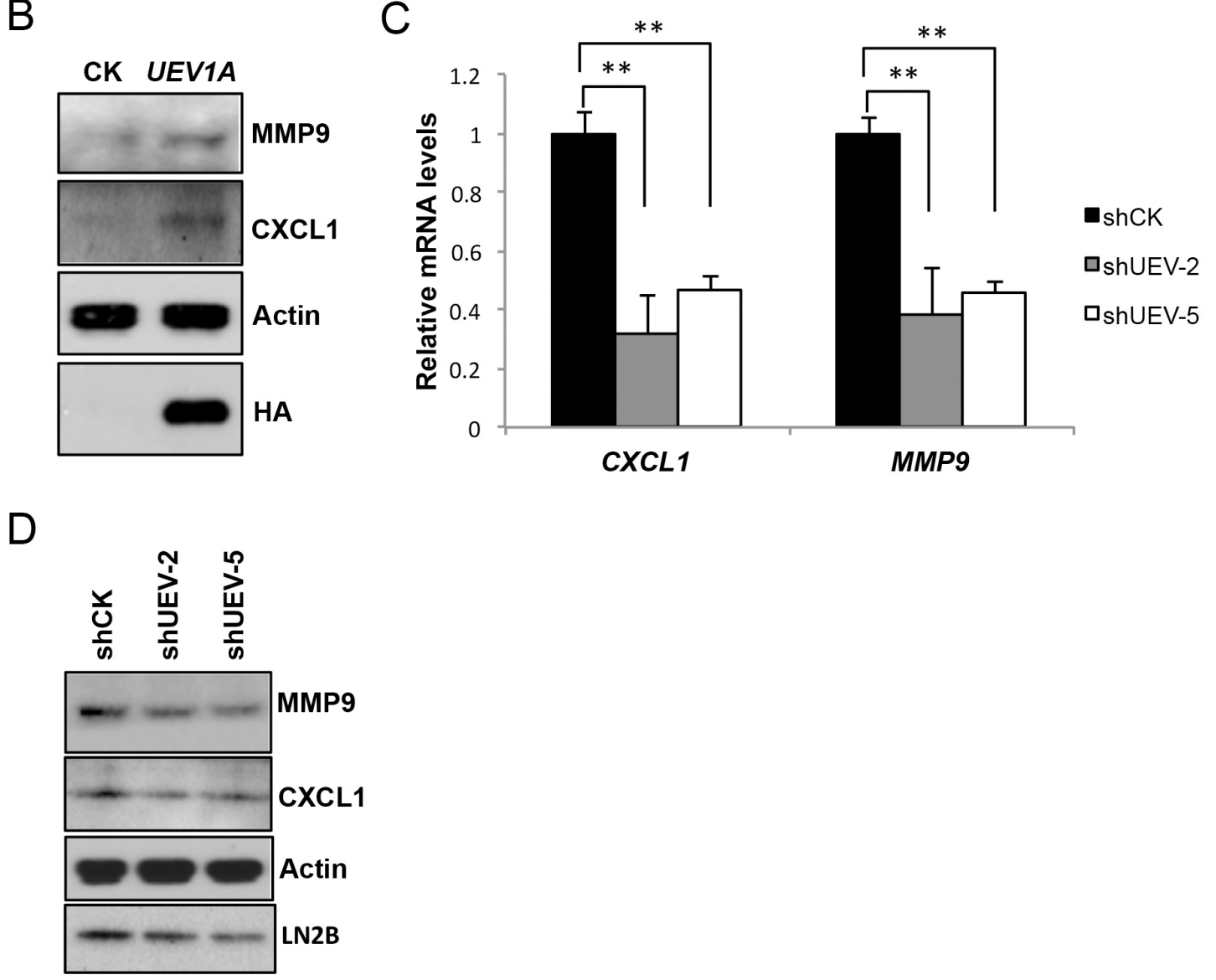

Figure 5: Uev1A positively regulates $C X C L 1$ and $M M P 9$ expression. (A) Transcript levels of selected putative NF- $\kappa \mathrm{B}$ target genes in HCT116-TR cells expressing different $U E V$ s as determined by qRT-PCR. (B) Elevated CXCL1 and MMP9 protein levels in $U E V 1 A$-overexpressed HCT116 cells as determined by western blot. Actin serves as a loading control and HA-tag shows ectopic UEV1A overexpression. (C) Relative transcript levels of CXCL1 and MMP9 in two independent shUEV1-transfected HCT116 cell lines as determined by qRT-PCR. (D) Relative protein levels of CXCL1 and MMP9 in two independent shUEV1-transfected HCT116 cell lines as determined by western blot. ${ }^{* *} P<0.01$. 
It has been reported that Uev1A works together with Ubc13 as a E2 complex to promote K63-linked polyubiquitination of target proteins in the $\mathrm{NF}-\kappa \mathrm{B}$ signaling pathway $[10,11]$. To ask whether Uev1A indeed requires Ubc13 for this process, we took two aproaches. First, a Mms2-F13E mutation is known to abolish the Mms2-Ubc13 complex formation [8], and similar mutations in Uev1A have been utilized to distinguish

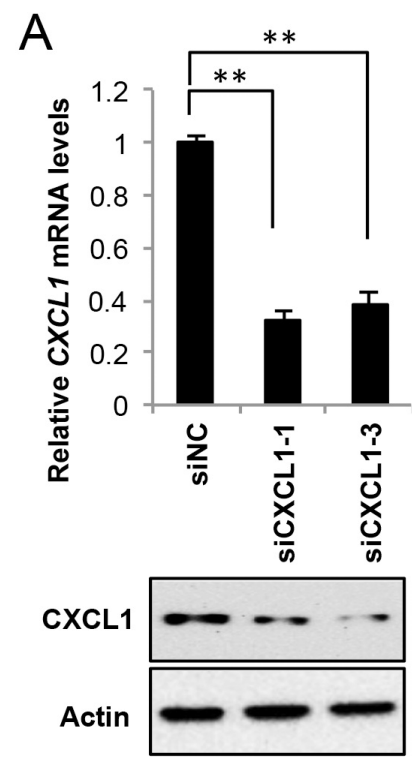

B
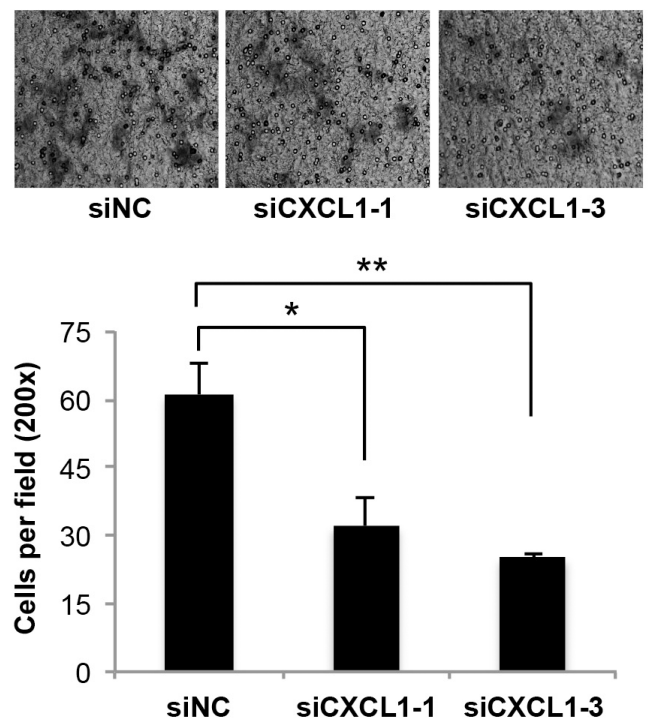

C

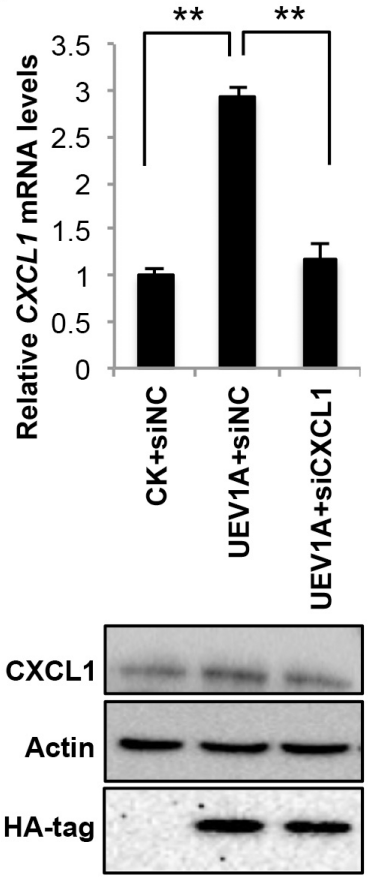

$\mathrm{D}$
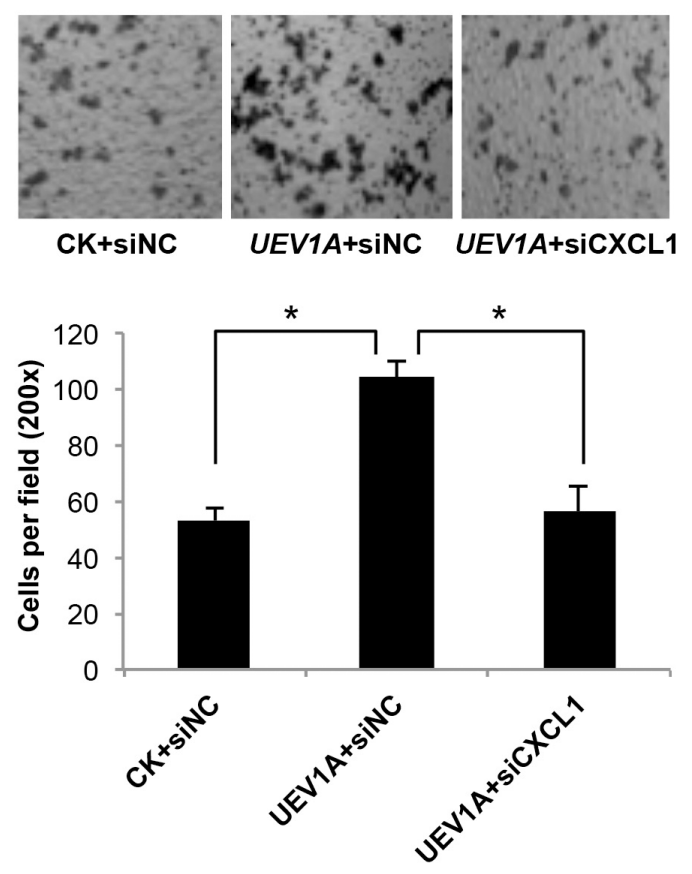

Figure 6: CXCL1 is a downstream effector for Uev1A-induced metastasis in HCT116 cells. (A) The mRNA (top panel) and protein (lower panel) levels of CXCL1 in CXCL1-depleted HCT116 cells by two independent CXCL1 siRNAs. siNC, control siRNA. (B) Representative images (upper panel) and quantitative analysis (lower panel) of cell invasive ability in Matrigel-coated transwells. HCT116 cells depleted of CXCL1 were subject to the transwell assay and at least 5 random fields were counted under a light microscope at 200x magnification. (C) The relative transcript (upper panel) and protein (lower panel) levels of CXCL1 in UEV1A-overexpressed HCT116-TR cells after CXCL1 depletion. (D) Representative images (upper panel) and quantitative analysis (lower panel) of cell invasive ability in Matrigel-coated transwells. UEV1A-overexpressed HCT116-TR cells depleted with CXCL1 were subject to the transwell assay and at least 5 random fields were counted under a light microscope at 200x magnification. ${ }^{*} P<0.05,{ }^{* *} P<0.01$. 
whether the Uev1 activity is dependent on Ubc13 [9, 30]. The Uev1A-F38E mutation completely abolished the physical interaction with Ubc13 in vivo (Figure 4C), and overexpression of such mutant gene failed to activate $\mathrm{NF}-\kappa \mathrm{B}$ (Figure 4A), indicating that the Uev1A-Ubc13 complex formation is absolutely required. Secondly, we attempted to deplete cellular Ubc13 in the UEV1A overexpressed cells to see whether limit of the Ubc13 level can reverse $U E V 1 A$-induced phenotypes. Indeed Ubc13 depletion increased phosphorylated $\mathrm{I} \kappa \mathrm{Ba}$, decreased total cellular I $\kappa \mathrm{Ba}$ and reduced nuclear p65 (Figure 4D), which led to decreased cell invasion (Figure 4E). Taken together, we conclude that $U E V 1 A$ overexpression resulted in increased Uev1A-Ubc13 complex formation, which promotes $\mathrm{NF}-\kappa \mathrm{B}$ signaling.

\section{$C X C L 1$ and $M M P 9$ genes are regulated by $U E V 1$}

Since NF- $\kappa \mathrm{B}$ is a transcription factor that regulates the expression of a large number of genes including those involved in tumorigenesis and metastasis, we assessed transcript levels of many established or tentative NF- $\kappa B$ target genes thought to be involved in cancer such as MMP1 [9], MMP9 [31], BCL2 [32], BCL6 [33], COX2

A

CXCL1 promoter (165 bp)
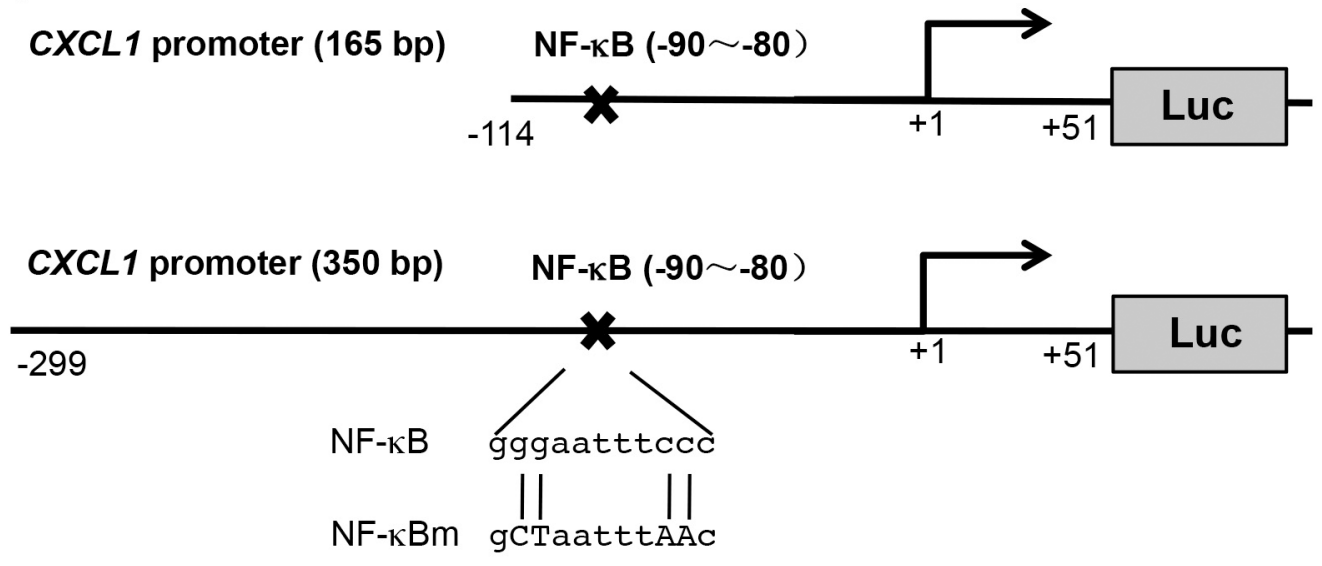

B

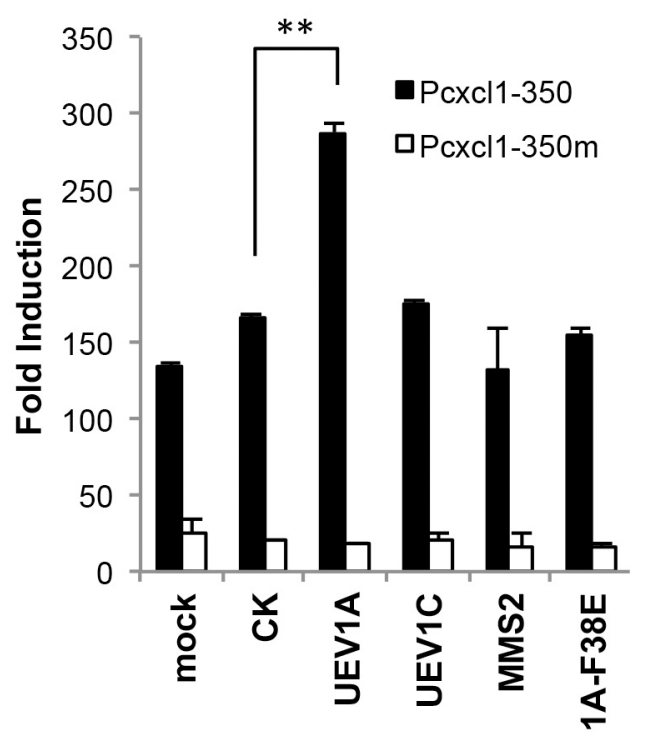

C

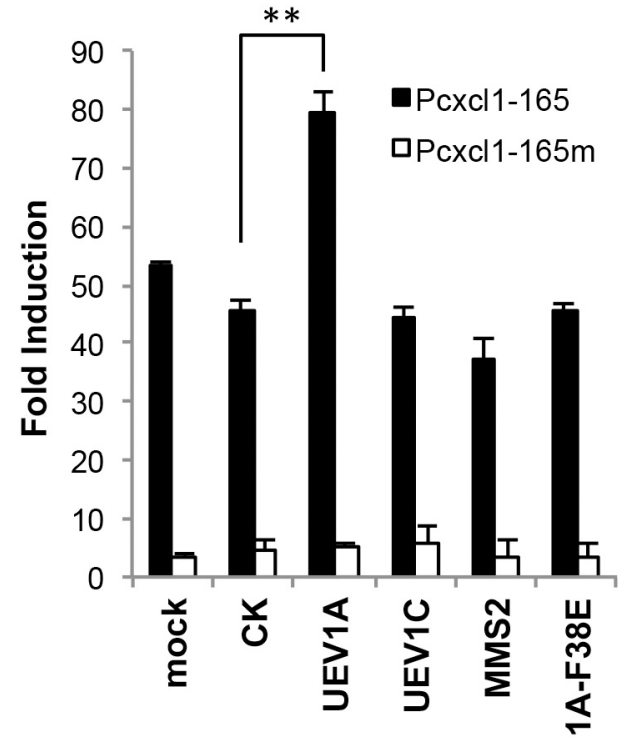

Figure 7: Uev1A regulates $C X C L 1$ expression through an $\mathrm{NF}-\kappa \mathrm{B}$ target sequence in the $C X C L 1$ promoter. (A) Schematic illustration of the 165-bp (Pcxcl1-165) and 350-bp (Pcxcl1-350) CXCL1 promoter luciferase (Luc) reporter constructs. The reported NF- $\mathrm{kB}$ binding site in the $C X C L 1$ promoter is located at $-90 \sim-80$ upstream of its start codon. The mutated sequences in the $\mathrm{P}_{c x c l l}-\mathrm{NF}-\kappa \mathrm{Bm}$ construct are also shown in capital letters. (B) The $P_{C X C L 1-350}-L u c$ reporter was co-transfected to HCT116 cells with constructs that overexpressed UEV1A, UEV1C, MMS2 or a mutant form of UEV1A (1A-F38E). 24 hours after transfection, luciferase activities were determined. The data were normalized to the activity of cells transfected with the empty vector (pGL4.2). (C) The $P_{C X C L I-165}-L u c$ reporter was co-transfected to HCT116 cells with constructs that overexpressed various $U E V$ constructs and experimental conditions were as described in $(\mathrm{B})\left({ }^{* *} P<0.01\right)$. 
[34], c-Myc [35], CCL2 [36] and CXCL1 [37], among which $C X C L 1$ and MMP9 transcripts were elevated by 2.9and 2.8-fold, respectively, in UEV1A-overexpression cells, but not in UEV1C or MMS2 overexpression cells (Figure 5A). CXCL1 and MMP9 protein levels were also elevated after $U E V 1 A$-overexpression (Figure 5B). This effect is completely dependent on Ubc13, as overexpression of UEV1A-F38E failed to induce CXCL1 and MMP9 (Figure 5A). Similarly, depletion of Uev1 in HCT116 cells significantly reduced $C X C L 1$ and $M M P 9$ transcript (Figure 5C) and protein (Figure 5D) levels, indicating that $C X C L 1$ and $M M P 9$ are regulated by Uev1 A-Ubc13. CXCL1 and $M M P 9$ transcript levels were also elevated by 6.8 -fold and 2.3-fold, respectively, in UEV1A-overexpressed DLD1 cells (Supplementary Figure 3D).

It has been previously reported that in MDA-MB-231 breast cancer cells, Uev1 A upregulates $M M P 1$, which is a dominant factor. $M M P 1$ can also be upregulated 2.2-fold in UEV1A-overexpressed HCT116-TR cells, but is not significantly different from levels in UEVIC- or MMS2overexpressed cells (Figure 5A). To ask whether MMP1 and MMP9 are critical effectors for Uev1A-induced metastasis, we depleted MMP1 (Supplementary Figure 6A) or MMP9 (Supplementary Figure 6B) by siRNA in HCT116 cells. The transwell assay results (Supplementary Figure 6C) show that $M M P 1$ depletion reduces HCT116 cell invasion while $M M P 9$ depletion does not.

\section{CXCL1 is a downstream effector for Uev1A- induced metastasis in colon cancer cells}

CXCL1 encodeschemokine (C-X-C motif) ligand 1 , also known as growth-regulated oncogene a (GRO) or melanoma growth stimulatory activity (MGSA). Chemokines are a group of small molecular cytokines that play important roles not only in the regulation of inflammation, wound healing, and development, but also in tumorigenesis and tumor metastasis through the G-protein-coupled receptor CXCR [37-43].

To ask whether CXCL1 is a critical effector for colon tumorigenesis and metastasis, we depleted CXCL1 by siRNA in HCT116 (Figure 6A) and DLD1 (Supplementary Figure 7A) cells. The depletion of CXCL1 significantly decreased the invasiveness of HCT116 and DLD1 cells as determined by a transwell assay (Figure 6B and Supplementary Figure 7B).

To ask whether Uev1A-induced CXCL1 expression plays a critical role in colon metastasis, first, we asked if depletion of CXCL1 reverses the effect of UEV1A overexpression. As seen in Figure 6C, 6D, CXCL1 depletion in UEV1A-overexpressed HCT116 cells reduced invasiveness to a level comparable to that of controltransfected cells. Second, we overexpressed CXCL1 in DLD1 cells about 5.4-fold to restore the CXCL1 mRNA level close to that in $U E V 1 A$-overexpressed DLD1 cells
(Supplementary Figure 7C). Compared with UEV1Aoverexpressed DLD1 cells and vector control, CXCL1 overexpression in DLD1 cells can also promote cell invasion (Supplementary Figure 7D). These results indicate that CXCL1 is a critical effector for Uev1Ainduced metastasis.

\section{Uev1A-Ubc13 control CXCL1 expression by regulating $\mathrm{NF}-\kappa \mathrm{B}$}

The expression of the GRO gene family is regulated transcriptionally and post-transcriptionally by a number of agents, including TNF $\alpha$ and IL-1, through the NF$\kappa \mathrm{B}$ binding site on the 5' regulatory region [44-46]. To ask whether Uev1A regulates $C X C L 1$ through NF- $\mathrm{kB}$, we cloned 350-bp and 165-bp human CXCL1 promoter sequences (Figure 7A) into pGL4.2 and then transfected them into HCT116 cells. After $40 \mathrm{ng} / \mathrm{ml}$ TNF- $\alpha$ induction for $2 \mathrm{hrs}$, the induced activity of each promoter construct can be detected by a luciferase assay (Supplementary Figure 8A, 8B). The promoter construct was then cotransfected with plasmids expressing UEV1A, UEV1A$F 38 E$ or an empty vector into HCT116 cells. A luciferase assay shows that UEV1A expression can activate the CXCL1 promoter and that this activation relies on its interaction with Ubc13, as the Uev1A-F38E substitution completely abolished the activation (Figure 7B, 7C). The NF- $\mathrm{kB}$ binding sites (-90 -80) in the CXCL1 promoter [44-46] was then mutated (Figure 7A) and this mutation completely abolished the activation of TNF- $\alpha$ induction (Supplementary Figure 8A, 8B) or induction by UEV1A expression (Figure 7B, 7C). Hence, overexpression of UEV1A, but not UEVIC or MMS2, can activate the wildtype $P_{C X C L I}-L u c$ reporter and this activation absolutely requires $U B C 13$ and the intact NF- $\mathrm{kB}$ target site.

\section{DISCUSSION}

The current study investigates roles of UEVIA in tumorigenesis using a colon cancer model. It was found that, with comparable levels of ectopic expression, only $U E V 1 A$, but not UEV1C or MMS2, is able to promote cell migration and invasion. Similarly, overexpression of UEV1A, but not UEV1C promotes tumor growth and metastasis in a xenograft mouse model. In a reverse experiment, depletion of Uev1 in cultured colon cancer cells significantly reduces cell invasion, as well as tumor growth and metastasis, indicating that Uev1A level plays a critical role in colon cancer tumorigenesis and metastasis.

Uev1A has been reported to activate NF- $\mathrm{BB}$ in HepG2 cells [23] and MDA-MB-231 cells [9]. To understand the molecular mechanism by which Uev1A promotes colon cancer metastasis, we demonstrated that overexpression of UEV1A, but not UEVIC or MMS2, is able to promote IKBa phorsphorylation and NF- 
$\kappa \mathrm{B}$ translocation into the nucleus, and that this effect absolutely relies on its physical interaction with Ubc13. Since NF- $\kappa \mathrm{B}$ is a transcription factor that regulates the expression of a large number of genes including those involved in cancer progression, we assessed the transcript levels of a panel of NF- $\kappa \mathrm{B}$ target genes thought to be involved in cancer and known to be regulated by Uev1A, including MMP1, MMP9 [9] and BCL2 [23]. However, NF- $\kappa \mathrm{B}$ activation by $U E V 1 A$ overexpression appears to induce different NF- $\mathrm{B}$ targeting genes in different types of tumor cell lines. For example, $M M P 1$ is a dominant factor for metastasis in MDA-MB-231 cells [9], but it is not upregulated significantly in UEV1Aoverexpressed HCT116 colon cancer cells. In contrast, CXCL1 and MMP9 are upregulated significantly in UEV1A-overexpressed HCT116 colon cancer cells. Since depletion of MMP9 had little effect on HCT116 cell invasion in the transwell assay, our attention focused on $C X C L 1$.

CXCL1 is upregulated in various tumors, such as breast cancer [37, 47], ovarian cancer [48], prostate cancer $[49,50]$, gastric cancer [51] and bladder cancer $[52,53]$. CXCL1 is implicated in tumorigenesis, angiogenesis, invasion, metastasis and resistance to several anti-cancer chemotherapies [37, 47]. Moreover, CXCL1 is identified as a distinctly overexpressed gene in human colon cancers by microarray analyses [54, 55] and it promotes the growth and invasion of colon cancer cells in a mouse xenograft tumor model $[42,43$, $56,57]$. To ask how Uev1A regulates $C X C L 1$, we used a luciferase assay to experimentally demonstrate that Uev1A can activate the wild-type $P_{C X C L 1}-L u c$ reporter and that this activation absolutely requires the NF- $\kappa \mathrm{B}$ target site located at -90 to -80 on the 5 ' regulatory region of CXCL1 [44-46].

Overall, overexpression of $U E V 1 A$ alone in HCT116 cells is sufficient to activate NF-кB, which in turn upregulates $C X C L 1$ expression to enhance colon cancer cell metastasis, and this phenomenon appears to be true in other colon cancer cells as well. These observations suggest a potential therapeutic target in the treatment of metastatic colon cancers.

\section{MATERIALS AND METHODS}

\section{Cell culture}

The human colon carcinoma cell line HCT116 was obtained from the American Type Culture Collection (ATCC). Human colon carcinoma DLD1, HT29, colo201, colo320, SW620 and human normal colon CCD-33Co cells were gifts from Dr. Keith Bonham in the Saskatoon Cancer Center. HCT116, DLD1, HT29, and SW620 cells were cultured in Dulbecco's minimum essential medium (DMEM) (Sigma); CCD-33Co cells were cultured in Eagle's minimum essential medium
(EMEM); colo201 and colo320 cells were cultured in Roswell Park Memorial Institute (RPMI) 1640 medium. All media were supplemented with $10 \%$ fetal bovine serum, 100 units $/ \mathrm{ml}$ penicillin, and $100 \mu \mathrm{g} / \mathrm{ml}$ streptomycin (Invitrogen). All cells were cultured in a $5 \% \mathrm{CO}_{2}$ atmosphere at $37^{\circ} \mathrm{C}$. HCT116-TR stable cell lines were created by transfecting HCT116 cell lines with pLenti6-TR-lentivirus (Invitrogen) and selecting with $10 \mu \mathrm{g} / \mathrm{ml}$ blasticidin (Invitrogen).

\section{Plasmids and pLentivirus vector preparation}

Human UEV1A, UEV1C and MMS2 open reading frames (ORFs) were amplified and cloned into a Doxinducible Tet-ON plasmid pcDNA4.0/TO/HA $(+)$ as described previously [9, 10]. The 350-bp and 165-bp human CXCL1 promoter sequences [44-46] were PCRamplified as KpnI-HindIII fragments and then cloned into the same sites of pGL4.2 (Invitrogen). The NF-кB target site was subsequently mutated by site-directed mutagenesis using a quick-exchange method (Stratagene). The sense primer for creating the NF-кB binding site mutation is 5'-CGATCTGGAACTCCGCTAATTTAACT GGCCCGGGGGCTCC-3' (mutated sequence underlined). The mutated Ubc13-binding site (F38E) in Uev1A was designed based on a previous study with Mms2-F13E [8]. The modified sequence for UEV1 shRNA(sc-38606-v) and negative control shRNA(sc-108080) delivered by lentiviral particles was from Santa Cruz Biotechnology, Inc. The UEV1 shRNA is a pool of concentrated, transduction-ready viral particales containing 3 target-specific constructs that encode 19-25 nt (plus hairpin) shRNA designed to knock down the target gene expression. Negative control shRNA lentiviral particles encode a scrambled shRNA sequence that will not lead to the specific degradation of any known cellular mRNA. The lentiviral particle infection of colon cancer cells was performed following instructions of the supplier. The CXCL1, MMP1 and $M M P 9$ siRNAs were purchased from Genepharma Co. Ltd (Shanghai, China). The sequence for CXCL1 siRNA-1 is 5'-CCAAGAACAUC CCAAAGUGUG-3', CXCL1 SiRNA-3 is 5'-AGTGACAAAUCCAACUGACC-3', MMP1 SiRNA is 5'- GCGUGUGACAGUAAGCUAA-3', $M M P 9$ siRNA is 5'-CGCUCAUGUACCCUAUGUA-3' and the negative control FAM siRNA is 5'-CUCCGAACGUGUCACGU-3'.

\section{RNA preparation and real-time RT-PCR (qRT- PCR)}

Total RNA was prepared from cultured colon cancer cells by using TRIzol reagent (Invitrogen). First-strand cDNA was synthesized from total RNA with SuperScript (Invitrogen) according to manufacturer's instructions. qRT-PCR analysis was performed on the iQ5 cycler (Bio-Rad). The specific primer sets were as follows: 
GADPH, 5'- GAAGGTGAAGGTCGGAGTC-3' and 5'- GAAGATGGTGATGGGATTTC-3'; UEV1A, 5' GAGAGGTTCAAGCGTCTTACCTGAA-3' and 5'-ACT GTGCCATCTCCTACTCCTTTCT-3'; UEV1C, 5'-GCA GCCACCACGGGCTCG-3' and 5'- CAATTATCAT CCCTGTCCATCTTGT-3'; MMS2, 5'- CGCTTGTTG GAAGAACTTGA-3' and 5'- CGGAGGAGCTTCTGG GTAT-3'; CXCL1 5'-CTTGCACTCGAGGTACCCAC TCCCTGGTGTCAT -3' and 5'- GGCCAGAAGCTT CCAGGAGCAGGAGCAGCAGT -3'; MMP1 5' - AAAT GCAGGAATTCTTTGGG-3' and 5'-ATGGTCCACAT CTGCTCTTG-3'; MMP9 5'-CATCGTCATCCAGTTTGG TG-3' and 5'- TCGAAGATGAAGGGGAAGTG-3'. The relative expression levels were calculated using the comparative cycle threshold (CT) method $\left(2^{-\Delta \mathrm{CT}}\right)$ by the CFX Manager software (Bio-Rad).

\section{Luciferase reporter assay}

Cells were seeded in 24-well plates at a density of $1 \times 10^{5}$. After $24 \mathrm{hrs}$, the cells were transfected using X-tremeGENE HP DNA Transfection Reagent (Roche). Briefly, luciferase reporter gene constructs (500 ng), pcDNA-Uevs plasmids (500 ng) and the pRL-SV40 Renilla luciferase construct ( $5 \mathrm{ng}$ ) (for normalization) were cotransfected into the wells. Cell extracts were prepared $48 \mathrm{hrs}$ after transfection and the luciferase activity was measured using the Dual-Luciferase reporter assay system (Promega).

\section{Preparation of nuclear fraction}

HCT116 and DLD1 cells were treated with $40 \mathrm{ng} /$ ml TNF- $\alpha$ for 2 hrs. Cells were washed, scraped with PBS, and centrifuged at $3,000 \mathrm{rpm}$ at $4^{\circ} \mathrm{C}$. The pellet was suspended in $10 \mathrm{mM}$ Tris $(\mathrm{pH} 8.0)$ with $1.5 \mathrm{mM}$ $\mathrm{MgCl}_{2}, 1 \mathrm{mM} \mathrm{DTT}$, and $0.1 \%$ NP-40, and incubated on ice for $15 \mathrm{~min}$. Nuclei were separated from cytosol by centrifugation at $12,000 \mathrm{rpm}$ at $4^{\circ} \mathrm{C}$ for $15 \mathrm{~min}$. The cytosolic supernatants were removed and the precipitated pellets were suspended in $10 \mathrm{mM}$ Tris ( $\mathrm{pH} \mathrm{8.0)}$ containing $100 \mathrm{mM} \mathrm{NaCl}$ and stored on ice for $30 \mathrm{~min}$. After agitation for $30 \mathrm{~min}$ at $4^{\circ} \mathrm{C}$, the lysate was centrifuged at 12,000 rpm for $15 \mathrm{~min}$ at $4^{\circ} \mathrm{C}$, and the supernatant was collected.

\section{Western blot analysis}

The total cell protein was extracted and protein concentration was determined as described previously [9, 10]. Cell extracts were electrophoresed in $10 \%$ or $15 \%$ SDS-PAGE gels, transferred to PVDF membrane, and incubated with specific primary antibodies. Monoclonal antibodies (mAbs) LN1 (anti-Uev1A), LN2B (antiUev1) and LN3 (anti-Uev1 and Mms2) were from the lab stock $[10,58]$. Primary antibodies against HA (sc-7392), NF- $\kappa$ B p65 (sc-372), $\beta$-tublin (sc-166729), Lamin B (sc-6216), MMP1 (sc-30069), and secondary goat antimouse antibody IgG-HRP (sc-2005) and goat anti-rabbit IgG-HRP (sc-2004) antibody were from Santa Cruz. The $\mathrm{P}-\mathrm{I} \kappa \mathrm{B} \alpha(\# 2859 \mathrm{~S})$ and I $\mathrm{B} \alpha$ (\#44D4) antibodies were from Cell Signaling Technology, anti-MMP9 (ab38898) and anti-GRO alpha/CXCL1 (ab86436) antibodies were from Abcam, and an anti-Actin antibody (BM0005) was from Boster.

\section{Cell invasion assays}

In vitro invasion assays were conducted using Transwells (Corning ${ }^{\circledR}$ 3422) with $8 \mu \mathrm{m}$ pore-size polycarbonate membrane filters in 24-well culture plates. The upper surface of the filter was coated with Matrigel (Becton Dickinson, Bedford, MA) in a volume of $50 \mu \mathrm{l}$ per filter. The Matrigel was dried and reconstituted at $37^{\circ} \mathrm{C}$ into a solid gel on the filter surface. The lower surface of the filter was coated with fibronectin $(20 \mu \mathrm{g} /$ $\mathrm{ml})$, vitronectin $(10 \mu \mathrm{g} / \mathrm{ml})$, collagen IV $(50 \mu \mathrm{g} / \mathrm{ml})$, or DMEM supplemented with $10 \%$ fetal bovine serum (FBS) as chemoattractants. After starving in FBS-free DMEM overnight, $2 \times 10^{4}$ cells were seeded in the upper chamber. The cells were allowed to invade for $48 \mathrm{hrs}$. Cells that invaded the lower surface of the filter were counted in 5 random fields under a light microscope at 200x magnification. Experiments were conducted at least in triplicate.

\section{Metastasis assay in a xenograft mouse model}

The experimental mouse work followed an animal care protocol approved by the University Committee on Animal Care and Supply, University of Saskatchewan. For the tumorigenesis assays, $1 \times 10^{6}$ cancer cells were injected subcutaneously into the lateral flanks of 4- to 5-weekold female athymic nude mice. The palpable tumor diameters were measured once per week. Tumor length (L) and width (W) were measured with a caliper, and the volume (V) was calculated by the following equation: $\mathrm{V}=\left(\mathrm{LxW}^{2}\right) / 2$. For experimental metastasis assays, the mice were sacrificed 5 weeks after cell injection. Organ samples were taken after sacrifice. Quantitative analysis of the in vivo organ metastasis was measured by the number of metastatic organs, 5 mice for each treatment.

\section{Case selection}

A set of histologically normal colonic mucosa $(\mathrm{N}=31)$, primary colon adenocarcinoma $(\mathrm{N}=46)$, and metastatic colon adenocarcinoma $(\mathrm{N}=56)$ were selected from the pathology archives of the Royal University Hospital/Saskatoon Health Region Department of Pathology and Laboratory Medicine. REB approval was obtained from the University of Saskatchewan. 


\section{Immunohistochemistry (IHC)}

Formalin-fixed colon tissues were paraffinembedded. The slides were deparaffinized and rehydrated. Antigen retrieval was done by cooking slides in a microwave oven in $1 \mathrm{mM}$ EDTA buffer at $\mathrm{pH} 9.0$ at highest power. Endogenous peroxidases were blocked. The respective slides were incubated with $200 \mu \mathrm{l}$ of the monoclonal antibodies (mAbs) LN1 (anti-Uev1A) and NF- $\kappa B$ (sc-372) primary antibodies at a 1/50 dilution and incubated overnight at $4{ }^{\circ} \mathrm{C}$ in a hydration chamber. Secondary antibody reactions for visualization of the bound primary $\mathrm{Ab}$ were performed using the Envision+ with DAB (3,3'-diaminobenzidine) as chromogen (Dako Canada). For color enhancement, subsequently the slides were incubated in a $2 \%$ copper sulphate solution for $5 \mathrm{~min}$. The results were scored by an experienced pathologist (ET). Uev1A and p65 were scored as either "positive" or "negative" using $10 \%$ positive cells as cut off point. In addition, the intensity of staining was recorded as "weak" $(1+)$, "moderate" $(2+)$, and "strong" $(3+)$. When samples of tumors were positive for Uev1A, they were generally diffusely positive. In contrast, when positive, the percent positive cells for p65 varied from one case to another. Therefore, Histological Score (H-Score) was used to record p65 expression. Nuclear and cytoplasmic staining was recorded independently for both p65 and Uev1A, and only nuclear positivity for p65 was used for further analysis and calculations. Subsequently, the H-score results were categorized for presentation purposes as follows: $0(\mathrm{H}$-score $<10)$, $1(\mathrm{H}$-score $=10-100), 2(\mathrm{H}$-score $101-200)$, and 3 $(\mathrm{H}$-score $=201-300)$. Results of the pathology readout were analyzed by SPSS statistical software by using the Spearman Correlation Test to compare levels of p65 and Uev1A expression and the Pearson Chi-Square Test to determine associations between Uev1A expression and diagnostic group. Results with $P$-values $<0.05$ were considered to be significant. Microscopic images were captured by a SPOT digital camera mounted in a light microscope.

\section{Statistical analysis}

The statistical significance of differential findings between the experimental and control groups was determined by a Student's $t$-test as implemented by Excel 2010 (Microsoft), and $P<0.05$ was considered significant.

\section{ACKNOWLEDGMENTS}

The authors wish to thank Dr. Keith Bonham for providing colon cancer cell lines, the University of Saskatchewan Lab Animal Services Unit for technical assistance and Michelle Hanna for proofreading the manuscript. This work was supported by a Saskatoon Royal University Hospital Foundation research grant to
ET and WX, and an operating grant from The Cancer Research Society Inc. to WX.

\section{CONFLICTS OF INTEREST}

The authors declare no conflicts of interest.

\section{REFERENCES}

1. Xiao W, Lin SL, Broomfield S, Chow BL, Wei YF. The products of the yeast MMS2 and two human homologs (hMMS2 and CROC-1) define a structurally and functionally conserved Ubc-like protein family. Nucleic Acids Res. 1998; 26:3908-3914.

2. Ma L, Broomfield S, Lavery C, Lin SL, Xiao W, Bacchetti $\mathrm{S}$. Up-regulation of CIR1/CROC1 expression upon cell immortalization and in tumor-derived human cell lines. Oncogene. 1998; 17:1321-1326.

3. Rothofsky ML, Lin SL. CROC-1 encodes a protein which mediates transcriptional activation of the human FOS promoter. Gene. 1997; 195:141-149.

4. Sancho E, Vilá MR, Sánchez-Pulido L, Lozano JJ, Paciucci R, Nadal M, Fox M, Harvey C, Bercovich B, Loukili N, Ciechanover A, Lin SL, Sanz F, et al. Role of UEV-1, an inactive variant of the E2 ubiquitin-conjugating enzymes, in in vitro differentiation and cell cycle behavior of HT-29-M6 intestinal mucosecretory cells. Mol Cell Biol. 1998; 18:576-589.

5. McKenna S, Moraes T, Pastushok L, Ptak C, Xiao W, Spyracopoulos L, Ellison MJ. An NMR-based model of the ubiquitin-bound human ubiquitin conjugation complex Mms2.Ubc13. The structural basis for lysine 63 chain catalysis. J Biol Chem. 2003; 278:13151-13158.

6. Moraes TF, Edwards RA, McKenna S, Pastushok L, Xiao W, Glover JN, Ellison MJ. Crystal structure of the human ubiquitin conjugating enzyme complex, hMms2-hUbc13. Nat Struct Biol. 2001; 8:669-673.

7. Hofmann RM, Pickart CM. Noncanonical MMS2-encoded ubiquitin-conjugating enzyme functions in assembly of novel polyubiquitin chains for DNA repair. Cell. 1999; 96:645-653.

8. Pastushok L, Moraes TF, Ellison MJ, Xiao W. A single Mms2 "key" residue insertion into a Ubc13 pocket determines the interface specificity of a human Lys63 ubiquitin conjugation complex. J Biol Chem. 2005; 280:17891-17900.

9. Wu Z, Shen S, Zhang Z, Zhang W, Xiao W. Ubiquitinconjugating enzyme complex Uev1A-Ubc13 promotes breast cancer metastasis through nuclear factor-small ka, CyrillicB mediated matrix metalloproteinase-1 gene regulation. Breast Cancer Res. 2014; 16:R75.

10. Andersen PL, Zhou H, Pastushok L, Moraes T, McKenna S, Ziola B, Ellison MJ, Dixit VM, Xiao W. Distinct regulation of Ubc13 functions by the two ubiquitin-conjugating enzyme variants Mms2 and Uev1A. J Cell Biol. 2005; 170:745-755. 
11. Deng L, Wang C, Spencer E, Yang L, Braun A, You J, Slaughter C, Pickart C, Chen ZJ. Activation of the IkappaB kinase complex by TRAF6 requires a dimeric ubiquitinconjugating enzyme complex and a unique polyubiquitin chain. Cell. 2000; 103:351-361.

12. Wang C, Deng L, Hong M, Akkaraju GR, Inoue J, Chen ZJ. TAK1 is a ubiquitin-dependent kinase of MKK, IKK. Nature. 2001; 412:346-351.

13. Shi CS, Kehrl JH. Tumor necrosis factor (TNF)-induced germinal center kinase-related (GCKR) and stress-activated protein kinase (SAPK) activation depends upon the E2/E3 complex Ubc13-Uev1A/TNF receptor-associated factor 2 (TRAF2). J Biol Chem. 2003; 278:15429-15434.

14. Zhou H, Wertz I, O'Rourke K, Ultsch M, Seshagiri S, Eby M, Xiao W, Dixit VM. Bcl10 activates the NF-kB pathway through ubiquitination of NEMO. Nature. 2004; 427:167-171.

15. Sun L, Deng L, Ea CK, Xia ZP, Chen ZJ. The TRAF6 ubiquitin ligase and TAK1 kinase mediate IKK activation by BCL10 and MALT1 in T lymphocytes. Mol Cell. 2004; 14:289-301.

16. Ea CK, Deng L, Xia ZP, Pineda G, Chen ZJ. Activation of IKK by TNFalpha requires site-specific ubiquitination of RIP1 and polyubiquitin binding by NEMO. Mol Cell. 2006; 22:245-257.

17. Liu S, Chen ZJ. Expanding role of ubiquitination in NF-kB signaling. Cell Res. 2011; 21:6-21.

18. Debatin KM. Apoptosis pathways in cancer and cancer therapy. Cancer Immunol Immunother. 2004; 53:153-159.

19. Ditsworth D, Zong WX. NF-kappaB: key mediator of inflammation-associated cancer. Cancer Biol Ther. 2004; 3:1214-1216.

20. Karin M, Ben-Neriah Y. Phosphorylation meets ubiquitination: the control of NF-[kappa]B activity. Annu Rev Immunol. 2000; 18:621-663.

21. Prasad S, Ravindran J, Aggarwal BB. NF-kB and cancer: how intimate is this relationship. Mol Cell Biochem. 2010; 336:25-37.

22. Lin A, Karin M. NF-kappaB in cancer: a marked target. Semin Cancer Biol. 2003; 13:107-114.

23. Syed NA, Andersen PL, Warrington RC, Xiao W. Uev1A, a ubiquitin conjugating enzyme variant, inhibits stress-induced apoptosis through NF-kappaB activation. Apoptosis. 2006; 11:2147-2157.

24. Brinkmann U, Gallo M, Polymeropoulos MH, Pastan I. The human CAS (cellular apoptosis susceptibility) gene mapping on chromosome 20q13 is amplified in BT474 breast cancer cells and part of aberrant chromosomes in breast and colon cancer cell lines. Genome Res. 1996; 6:187-194.

25. Kallioniemi A, Kallioniemi OP, Piper J, Tanner M, Stokke T, Chen L, Smith HS, Pinkel D, Gray JW, Waldman FM. Detection and mapping of amplified DNA sequences in breast cancer by comparative genomic hybridization. Proc Natl Acad Sci USA. 1994; 91:2156-2160.

26. Tanner MM, Tirkkonen M, Kallioniemi A, Holli K, Collins C, Kowbel D, Gray JW, Kallioniemi OP, Isola J. Amplification of chromosomal region 20q13 in invasive breast cancer: prognostic implications. Clin Cancer Res. 1995; 1:1455-1461.

27. El-Rifai W, Harper JC, Cummings OW, Hyytinen ER, Frierson HF Jr, Knuutila S, Powell SM. Consistent genetic alterations in xenografts of proximal stomach and gastroesophageal junction adenocarcinomas. Cancer Res. 1998; 58:34-37.

28. Savelieva E, Belair CD, Newton MA, DeVries S, Gray JW, Waldman F, Reznikoff CA. 20q gain associates with immortalization: 20q13.2 amplification correlates with genome instability in human papillomavirus 16 E7 transformed human uroepithelial cells. Oncogene. 1997; 14:551-560.

29. Pulvino M, Liang Y, Oleksyn D, DeRan M, Van Pelt E, Shapiro J, Sanz I, Chen L, Zhao J. Inhibition of proliferation and survival of diffuse large B-cell lymphoma cells by a small-molecule inhibitor of the ubiquitin-conjugating enzyme Ubc13-Uev1A. Blood. 2012; 120:1668-1677.

30. Zhang W, Zhuang Y, Zhang Y, Yang X, Zhang H, Wang G, Yin W, Wang R, Zhang Z, Xiao W. Uev1A facilitates osteosarcoma differentiation by promoting Smurf1mediated Smad1 ubiquitination and degradation. Cell Death Dis. 2017; 8:e2974.

31. Wang X, Lu H, Urvalek AM, Li T, Yu L, Lamar J, DiPersio CM, Feustel PJ, Zhao J. KLF8 promotes human breast cancer cell invasion and metastasis by transcriptional activation of MMP9. Oncogene. 2011; 30:1901-1911.

32. Chen GG, Liang NC, Lee JF, Chan UP, Wang SH, Leung $\mathrm{BC}$, Leung KL. Over-expression of Bcl-2 against Pteris semipinnata L-induced apoptosis of human colon cancer cells via a NF-kappa B-related pathway. Apoptosis. 2004; 9:619-627.

33. Hideshima T, Mitsiades C, Ikeda H, Chauhan D, Raje N, Gorgun G, Hideshima H, Munshi NC, Richardson PG, Carrasco DR, Anderson KC. A proto-oncogene BCL6 is up-regulated in the bone marrow microenvironment in multiple myeloma cells. Blood. 2010; 115:3772-3775.

34. Jung YJ, Isaacs JS, Lee S, Trepel J, Neckers L. IL-1betamediated up-regulation of HIF-1alpha via an NFkappaB/ COX-2 pathway identifies HIF-1 as a critical link between inflammation and oncogenesis. FASEB J. 2003; 17:2115-2117.

35. Duyao MP, Kessler DJ, Spicer DB, Bartholomew C, Cleveland JL, Siekevitz M, Sonenshein GE. Transactivation of the c-myc promoter by human $\mathrm{T}$ cell leukemia virus type 1 tax is mediated by NF kappa B. J Biol Chem. 1992; 267:16288-16291.

36. Feng Y, Cai ZR, Tang Y, Hu G, Lu J, He D, Wang S. TLR4/NF-kappaB signaling pathway-mediated and 
oxLDL-induced up-regulation of LOX-1, MCP-1, and VCAM-1 expressions in human umbilical vein endothelial cells. Genet Mol Res. 2014; 13:680-695.

37. Acharyya S, Oskarsson T, Vanharanta S, Malladi S, Kim J, Morris PG, Manova-Todorova K, Leversha M, Hogg N, Seshan VE, Norton L, Brogi E, Massague J. A CXCL1 paracrine network links cancer chemoresistance and metastasis. Cell. 2012; 150:165-178.

38. Nanney LB, Mueller SG, Bueno R, Peiper SC, Richmond A. Distributions of melanoma growth stimulatory activity of growth-regulated gene and the interleukin- 8 receptor B in human wound repair. Am J Pathol. 1995; 147:1248-1260.

39. Ahuja SK, Murphy PM. The CXC chemokines growthregulated oncogene (GRO) alpha, GRObeta, GROgamma, neutrophil-activating peptide-2, and epithelial cell-derived neutrophil-activating peptide-78 are potent agonists for the type $\mathrm{B}$, but not the type $\mathrm{A}$, human interleukin- 8 receptor. $\mathrm{J}$ Biol Chem. 1996; 271:20545-20550.

40. Rennekampff HO, Hansbrough JF, Woods V Jr, Doré C, Kiessig V, Schröder JM. Role of melanoma growth stimulatory activity (MGSA/gro) on keratinocyte function in wound healing. Arch Dermatol Res. 1997; 289:204-212.

41. Jonsson D, Amisten S, Bratthall G, Holm A, Nilsson BO. LPS induces GROalpha chemokine production via NF-kappaB in oral fibroblasts. Inflamm Res. 2009; 58:791-796.

42. Ogata H, Sekikawa A, Yamagishi H, Ichikawa K, Tomita S, Imura J, Ito Y, Fujita M, Tsubaki M, Kato H, Fujimori T, Fukui H. GROalpha promotes invasion of colorectal cancer cells. Oncol Rep. 2010; 24:1479-1486.

43. Kuo PL, Shen KH, Hung SH, Hsu YL. CXCL1/GROalpha increases cell migration and invasion of prostate cancer by decreasing fibulin-1 expression through NF-kappaB/ HDAC1 epigenetic regulation. Carcinogenesis. 2012; 33:2477-2487.

44. Wood LD, Richmond A. Constitutive and cytokine-induced expression of the melanoma growth stimulatory activity/ GRO alpha gene requires both NF-kappa B and novel constitutive factors. J Biol Chem. 1995; 270:30619-30626.

45. Shattuck RL, Wood LD, Jaffe GJ, Richmond A. MGSA/ GRO transcription is differentially regulated in normal retinal pigment epithelial and melanoma cells. Mol Cell Biol. 1994; 14:791-802.

46. Anisowicz A, Messineo M, Lee SW, Sager R. An NF-kappa B-like transcription factor mediates IL-1/TNF-alpha induction of gro in human fibroblasts. J Immunol. 1991; 147:520-527.

47. Bachmeier BE, Mohrenz IV, Mirisola V, Schleicher E, Romeo F, Hohneke C, Jochum M, Nerlich AG, Pfeffer U. Curcumin downregulates the inflammatory cytokines CXCL1 and -2 in breast cancer cells via NFkappaB. Carcinogenesis. 2008; 29:779-789.

48. Yang G, Rosen DG, Zhang Z, Bast RC Jr, Mills GB, Colacino JA, Mercado-Uribe I, Liu J. The chemokine growth-regulated oncogene 1 (Gro-1) links RAS signaling to the senescence of stromal fibroblasts and ovarian tumorigenesis. Proc Natl Acad Sci U S A. 2006; 103:16472-16477.

49. Moore BB, Arenberg DA, Stoy K, Morgan T, Addison CL, Morris SB, Glass M, Wilke C, Xue YY, Sitterding S, Kunkel SL, Burdick MD, Strieter RM. Distinct CXC chemokines mediate tumorigenicity of prostate cancer cells. Am J Pathol. 1999; 154:1503-1512.

50. Engl T, Relja B, Blumenberg C, Muller I, Ringel EM, Beecken WD, Jonas D, Blaheta RA. Prostate tumor CXC-chemokine profile correlates with cell adhesion to endothelium and extracellular matrix. Life Sci. 2006; 78:1784-1793.

51. Wei ZW, Xia GK, Wu Y, Chen W, Xiang Z, Schwarz RE, Brekken RA, Awasthi N, He YL, Zhang CH. CXCL1 promotes tumor growth through VEGF pathway activation and is associated with inferior survival in gastric cancer. Cancer Lett. 2015; 359:335-343.

52. Miyake M, Lawton A, Goodison S, Urquidi V, GomesGiacoia E, Zhang G, Ross S, Kim J, Rosser CJ. Chemokine (C-X-C) ligand 1 (CXCL1) protein expression is increased in aggressive bladder cancers. BMC Cancer. 2013; 13:322.

53. Kawanishi H, Matsui Y, Ito M, Watanabe J, Takahashi T, Nishizawa K, Nishiyama H, Kamoto T, Mikami Y, Tanaka Y, Jung G, Akiyama H, Nobumasa H, et al. Secreted CXCL1 is a potential mediator and marker of the tumor invasion of bladder cancer. Clin Cancer Res. 2008; 14:2579-2587.

54. Williams NS, Gaynor RB, Scoggin S, Verma U, Gokaslan T, Simmang C, Fleming J, Tavana D, Frenkel E, Becerra C. Identification and validation of genes involved in the pathogenesis of colorectal cancer using cDNA microarrays and RNA interference. Clin Cancer Res. 2003; 9:931-946.

55. Notterman DA, Alon U, Sierk AJ, Levine AJ. Transcriptional gene expression profiles of colorectal adenoma, adenocarcinoma, and normal tissue examined by oligonucleotide arrays. Cancer Res. 2001; 61:3124-3130.

56. Bandapalli OR, Ehrmann F, Ehemann V, Gaida M, MacherGoeppinger S, Wente M, Schirmacher P, Brand K. Downregulation of CXCL1 inhibits tumor growth in colorectal liver metastasis. Cytokine. 2012; 57:46-53.

57. Wang D, Wang H, Brown J, Daikoku T, Ning W, Shi Q, Richmond A, Strieter R, Dey SK, DuBois RN. CXCL1 induced by prostaglandin E2 promotes angiogenesis in colorectal cancer. J Exp Med. 2006; 203:941-951.

58. Pelzer L, Pastushok L, Moraes T, Mark Glover JN, Ellison MJ, Ziola B, Xiao W. Biological significance of structural differences between two highly conserved Ubc variants. Biochem Biophys Res Commun. 2009; 378:563-568. 